\title{
Building Bridges between Biotechnology and Chemistry - Oreste Ghisalba's Pioneering Activities, Publications and Programs
}

\author{
Roland Wohlgemuth*ab
}

\begin{abstract}
This contribution focusses on Oreste Ghisalba's pioneering activities in both fundamental as well as applied research in biocatalysis and his work on building bridges not only between biotechnology and chemistry, but also culturally, geographically and between academia and industry. His scientific work published in journals, books and conferences will be reviewed and his teaching at ETH Zurich and the University of Basel will be highlighted. Furthermore, an appreciation will be given of his broad knowledge and vision in shaping the activities of the Swiss Coordination Committee Biotechnology (SKB), the Swiss-Japanese Meetings in Biotechnology, conferences and research programs such as the Swiss Priority Program Biotechnology (SPP Biotech) of the Swiss National Science Foundation.
\end{abstract}

Keywords: Enzymes in organic synthesis · Industrial biotransformations · Microbial biodegradation · Microbial biosynthesis - Microbial enzymes

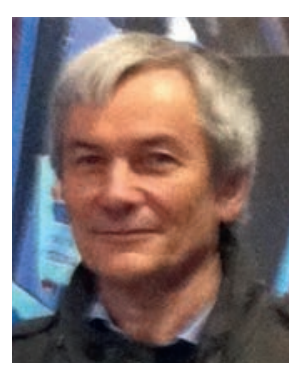

After studying chemistry at the University of Basel, Roland Wohlgemuth moved to the Biocenter (University of Basel) to work with Prof. Joachim Seelig. After obtaining his Dr. phil. II in Biophysical Chemistry in 1979 and postdoctoral research with Prof. Seelig he moved to UC Berkeley in 1980 to work on artificial photosynthesis with Prof. Melvin Calvin until 1983, and then moved back to Switzerland. As head of the bioanalytical laboratory he built up biochemistry/ biotechnology at Fluka in Buchs SG and in 1989 became head of the biochemistry department, which was developed further after the acquisition of Fluka by Sigma-Aldrich. After SigmaAldrich was acquired by Merck KGaA he continued to work for Sigma-Aldrich/Merck KGaA and accepted in 2017 an offer to move from industry to Lodz University of Technology in Poland, where he is now working as Professor in the Institute of Molecular and Industrial Biotechnology. He is member of the STRENDA Commission and serves on various boards of scientific journals. He is president of the Swiss Coordination Committee Biotechnology (SKB), ESAB chairman, executive board member of the European Federation of Biotechnology (EFB) and chairman Task Group Bioeconomy.

\section{Studies from Chemistry to Biochemistry, Molecular Biology and Microbiology}

Oreste Ghisalba and I got to know each other during our chemistry studies at the University of Basel, which provided an inspiring and stimulating environment. A professional education as laboratory technician (textile chemistry and dye-stuff application) at CIBA Ltd. in Basel, Switzerland, studying with AKAD to obtain the Swiss Matura Type B and continued work at CIBA Ltd. and in clinical chemistry at the Cantonal Hospital Basel provided a solid background and work experience for Oreste Ghisalba to start his chemistry studies. At the University of Basel Oreste Ghisalba pursued his studies of all branches of chemistry with great interest, motivation and focus, while at the same time also looking across borders and maintaining a genuine interest and curiosity in related fields of natural sciences and beyond. From the time spent together with Oreste Ghisalba throughout our studies at the University of Basel, the author recollects many great and critical discussions on visions for the future at different levels, on needs for improvements and the bottlenecks preventing improvements, spanning a wide range of areas from chemistry, mathematics, biology, philosophy and culture. Among the different topics in chemistry, the broad field of organic chemistry caught Oreste Ghisalba's attention early on and the organic chemistry lectures of Prof. Christoph Tamm, who was one of the Biocenter cofounders and later rector of the University of Basel, provided inspiring perspectives on natural products and their synthesis and gained special attention. The creation of the Biocenter of the University of Basel interested Oreste Ghisalba already during his studies in chemistry. At the Biocenter highly attractive new courses in the life sciences were offered: biochemistry by Prof. Jeff Schatz, who was awarded numerous prizes for his pioneering research on mitochondria, influenced the research culture of a whole generation and was an excellent communicator of his knowledge and thoughts, not only to a scientific audience but also to a general audience as an author of books and essays; molecular biology by Prof. Eduard Kellenberger, who was dedicated to electron microscopy, bacteria and phage genetics and who had pioneered the creation of the first Institute of Molecular Biology in Switzerland at the University of Geneva and took part in founding the European Molecular Biology Organisation (EMBO); molecular genetics and molecular microbiology by Prof. Werner Arber, who 
was awarded the 1978 Nobel Prize in Physiology and Medicine; and last but not least, microbiology by Prof. Jakob Nüesch, who was working in pharmaceutical research at Ciba-Geigy. It was therefore no surprise that in addition to completing his studies with the diploma in chemistry, Oreste Ghisalba also obtained the Swiss certificate in Molecular Biology (Swiss Commission for Molecular Biology, SKMB). It was at the Biocenter that Oreste Ghisalba met Prof. Jakob Nüesch, who at that time gave lectures in microbiology, was Head of Microbial Fermentation, then Head of Pharmaceutical Research at Ciba-Geigy and later became president of ETH Zurich. The opportunity to start his dissertation work with Prof. Nüesch at the industry-academia interface fitted very well with Oreste Ghisalba's broad interests. The combination of the molecular background knowledge from chemistry with the methods of microbiology was very attractive to Oreste Ghisalba, especially as the biosynthetic power of microbial systems could be applied for the preparation of valuable antibiotics, whose value for the society in improving and saving numerous lives in the past, the present and the future cannot be overemphasized, The story of the rifamycin antibiotics is a very nice example of successful interactions between researchers in biotechnology and chemistry, from their discovery in a screening program for new antimicrobials as a complex mixture of microbial metabolites ${ }^{[1]}$ in the fermentation of Streptomyces mediterranei, their isolation and purification to the determination of the molecular structures ${ }^{[2]}$ and their biological activities, ${ }^{[3]}$ the development of synthetic methodologies and the manufacturing of new semisynthetic derivatives and analogues towards effective antibiotics for clinical applications. ${ }^{[4]}$ Oreste Ghisalba therefore decided to work with Prof. Jakob Nüesch on the topic of the biosynthesis of the chromophore of the antibiotic rifamycin from Nocardia mediterranei. ${ }^{[5]}$ Large numbers of rifamycin derivatives and analogues have been prepared primarily by Ciba-Geigy Basel in Switzerland and Lepetit Research Laboratories Milano in Italy, leading to a number of important antimicrobial agents (Fig. 1), which have been employed in the therapy of major infectious diseases. ${ }^{[6]}$ The great number of modifications of the basic rifamycin scaffold as well as the highly specific action against the enzymes for polynucleotide biosynthesis are also of particular interest to molecular biology.

The actinomycete, from which a complex mixture of rifamycins were first isolated by Lepetit in 1959, was first named Streptomyces mediterranei, then later classified as Nocardia mediterranei, which was the name used at the time when Oreste Ghisalba carried out his work and published his discoveries, and finally named Amycolatopsis mediterranei. ${ }^{[6]}$ After receiving in 1978 his PhD in microbiology at the University of Basel, Oreste Ghisalba worked from 1978 to 1980 as postdoctoral fellow at Ciba-Geigy in Basel.

\section{Microbial Biosynthesis}

\subsection{Antibiotics}

In the area of antibiotics, Oreste Ghisalba isolated and characterized biochemically the first two aromatic amino acid-deficient mutants of $N$. mediterranei which provide genetic evidence that shikimate pathway intermediates must be involved in the rifamycin chromophore biosynthesis. ${ }^{[5,7-9]}$ Starting from a high rifamycin B producer N. mediterranei N813 strain, Oreste Ghisalba investigated biochemically and genetically the much less rifamycin B-producing mutant A8, which is auxotrophic for aromatic amino acids, defective in the formation of shikimate pathway products as well as rifamycin biosynthesis. This mutant was shown to accumulate D-ribulose in the fermentation broth as main product within a pentose mixture, while transketolase activity was not detected when using crude extracts and pentose phosphate in $v i$ tro to measure D-sedoheptulose-7-phosphate. ${ }^{[8]}$ As the shikimate pathway was the only route for the biotransformation of D-sedoheptulose-7-phosphate to aromatic amino acids and vitamins, the conclusion of the biochemical and genetic investigations was that a shikimate pathway intermediate must be further transformed to the building block of the rifamycin chromophore containing seven carbons and amino group. The A10 mutant, a derivative of the $N$. mediterranei N813 strain and an aromatic amino acid auxotroph, was found to produce, unlike the A8 mutant, rifamycin B in the same amounts as strain N813 and to accumulate shikimate and 3-dehydroshikimate in the fermentation broth. ${ }^{[9]}$ It seemed very likely that the missing enzyme in the A10 mutant was the shikimate kinase, as in in vitro experiments using shikimate, ATP and crude extracts of A10 as well as N813 shikimate-3-phosphate could not be detected. Because the A10 mutant had only a defect in aromatic amino acid biosynthesis and not in rifamycin biosynthesis, the building block of the rifamycin chromophore containing seven carbons and an amino group was clearly considered to originate from a shikimate pathway intermediate which is not located beyond shikimate. Taking together all results from bio-

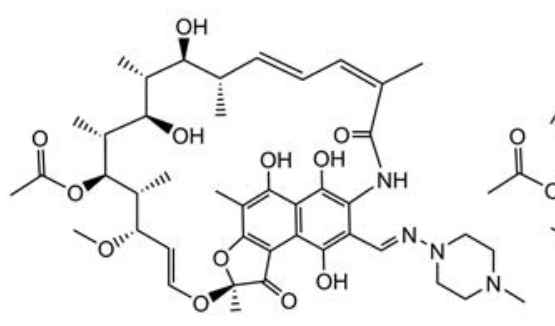

Rifampicin

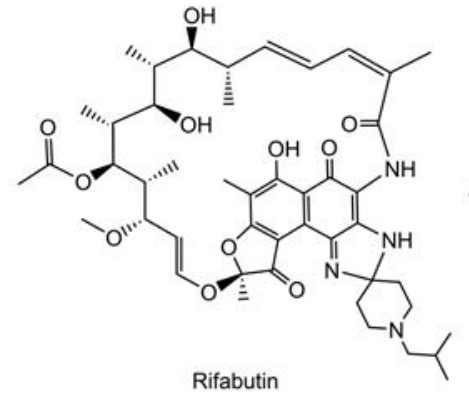

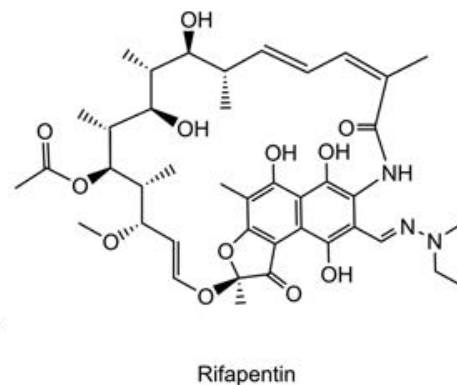

Rifapentin

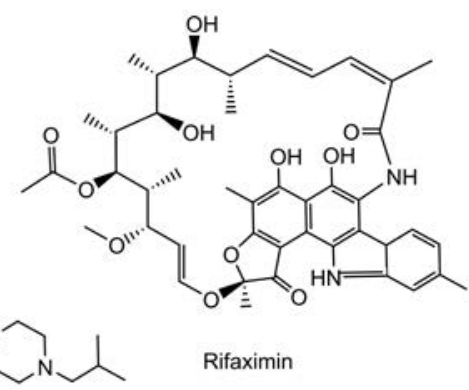

Fig. 1. Rifamycin antibiotics in the treatment of major infectious diseases. 
chemical and genetic investigations enable the definite localization of the origin of building block of the rifamycin chromophore containing seven carbons and an amino group between shikimate and 3-deoxy-D-arabinoheptulosonic acid-7-phosphate (DAHP), thus reducing possible precursors to only four shikimate pathway intermediates between DAHP and shikimic acid. ${ }^{[9]}$

The biosynthesis of rifamycin $\mathrm{W}$ was investigated in fermentations of $N$. mediterranei $\mathrm{F} 1 / 24$, another mutant strain obtained by UV-irradiation from N813, which was shown to accumulate a number of novel ansamycins, from which the biologically inactive 8-deoxyrifamycin W (protorifamycin I), a direct biosynthetic precursor of rifamycin $\mathrm{W}$, was purified and identified as the main component. ${ }^{[10]}$ The isolation of the minor and biologically inactive compounds proansamycin B-MI and protorifamycin I-MI, which contain an open ansa chain, led to their identification as degradation products of the postulated proansamycin $\mathrm{B}$ and of protorifamycin I, respectively, whereby the bond between $\mathrm{C}(5)$ and $C(11)$ seemed to be cleaved by a non-specific reaction for ansamycins with a proto-rifamycin I-type chromophore. ${ }^{[11]}$ From $N$. mediterranei $\mathrm{F} 1 / 24$, which produced protorifamycin I, nine further products were isolated and identified as belonging to two structure types: six of these minor compounds were direct modifications of protorifamycin I (type 1), namely: proto-rifamycin I-lactone, 23-ketoprotorifamycin I, 30-hydroxyprotorifamycin I, 20-hydroxyprotorifamycin I, 13-hydroxyprotorifamycin I and 23-acetoxyprotorifamycin I, while three compounds were defective rifamycins (type 2), namely: 8-deoxyrifamycin B, 8-deoxyrifamycin S (SV) and 8-deoxy-3-hydroxyrifamycin S (SV). ${ }^{[12}$ The isolation, purification and structural identification of these compounds supplied considerable biosynthetic information and relations between the structure and biological activity of antibiotics.

As all the UV-mutants that did not produce rifamycin were derived from $N$. mediterranei A10 and blocked in either of the four shikimate pathway enzymes shikimate reductase, 3-dehydroquinate dehydratase, 3-dehydroquinate synthetase or DAHP synthetase, still excreted shikimate and no other shikimate pathway intermediates, it became clear that the rifamycin mutation was not due to a second block in the shikimate pathway before the branch point but was due to additional blocks in the rifamycin biosynthesis behind the branch point. ${ }^{[13]}$ Instead of accumulating rifamycin $\mathrm{B}$, some of the strict rifamycin non-producing UV-mutants accumulated, depending on the isolation procedure, 2,6-dimethyl-3,5,7-trihydroxy-7-(3'-amino-5'-hydroxyphenyl)2,4-hepta-dienoic acid either as the free acid or as its 1,5-lactone, an aromatic precursor, consistent with the building block of the rifamycin chromophore containing seven carbons and an amino group, very early in rifamycin biosynthesis. ${ }^{[13]}$ This provided strong evidence that the building block of the rifamycin chromophore containing seven carbons and an amino group for the ansamycin biosynthesis was 3-amino-5-hydroxybenzoic acid or its coenzyme A derivative, respectively. Experiments with the strains $N$. mediterranei A8 (transketolase ${ }^{-}$, aro $^{-}$, rifamycin ${ }^{-}$) and double mutant P14 (1. mutation: aro- ${ }^{-}$, shikimate accumulation, 2. mutation: rifamycin-, accumulation of 2,6-dimethyl-3,5,7trihydroxy-7-(3'-amino-5'-hydroxyphenyl)-2,4-heptadienoic acid $\mathrm{P} 8 / 1-\mathrm{OG})$ demonstrated clearly that for rifamycin B production strain A8 utilized a metabolite which was excreted by strain $\mathrm{P} 14^{[14]}$ and cofermentation of strain A8 with strain P14 restored the original rifamycin production capacity of the parent strain N813. 3-Amino-5-hydroxybenzoic acid has been synthesized as pure compound and was demonstrated to substitute for the seven-carbon amino unit, as the original rifamycin production capacity of the parent strain N813 could also be restored by supplementing the medium of $N$. mediterranei strain A8 with it, thus establishing 3-amino-5-hydroxy-benzoic acid as direct origin of the building block of the rifamycin chromophore con- taining seven carbons and an amino group, which could then be identified with 3-amino-5-hydroxybenzoyl-coenzyme A. ${ }^{[14]}$ After the preparation of that manuscript it came to the knowledge of the authors that Kibby et al. had shown that synthetic $\left[{ }^{14} \mathrm{C}\right.$-carboxy]-3-amino-5-hydroxybenzoic acid was incorporated into actamycin and ansamycin similar to naphthomycin and that these authors had independently drawn the same conclusion concerning the direct origin of the building block of the rifamycin chromophore containing seven carbons and amino group. ${ }^{[15]}$ Two different approaches by two groups for two different ansamycins have therefore given strong support for a biosynthetic model proposed by both groups for all ansamycin types, such as rifamycins, streptovaricins, geldanamycins or maytansins, starting from shikimate pathway intermediates using the simple benzoic acid substituted by an aminogroup in the 3-position and a hydroxygroup in the 5-position as key metabolite for the biosynthetic construction of the rifamycin chromophore containing seven carbons and an amino group.

Reinvestigating how rifamycin $\mathrm{S}$ is converted to rifamycin $\mathrm{B}$ and rifamycin $\mathrm{L}$ excluded rifamycin 0 as common intermediate $\mathrm{B}$ and $\mathrm{L}$, as it could be shown that from rifamycin S (SV) different pathways with different three-carbon precursors lead to the glycolic acid moieties of rifamycin B and rifamycin L. ${ }^{[16]}$ Mutasynthesis experiments with the $N$. mediterranei A8 strain indicated for rifamycin biosynthesis that 3-amino-5-hydroxybenzoic acids substituted in the 4-position cannot substitute for the building block of the rifamycin chromophore containing seven carbons and an amino group and that the activating enzyme system for its biosynthesis seems to be highly specific. [17] Indirect indication for DAHP as the branch point intermediate was obtained from experiments with $N$. mediterranei mutant $\mathrm{B} 9$, which is aro $^{-}$, 3 -dehydroquinate synthetase ${ }^{-}$and rifamycin ${ }^{+}$and from supplementation studies carried out with $N$. mediterranei mutant A8. [18] The detailed pathway of the microbial biosynthesis of rifamycins (Fig. 2) has been of great importance for producing industrial antibiotics and involves chain extension by propionate and acetate units from 3-amino-5-hydroxybenzoic acid. ${ }^{[19]}$

In recognition of the 1984 Award of the Swiss Association of Chemists which Oreste Ghisalba received for his contributions to rifamycin biosynthesis and biotechnology, he described in a short review how rifamycins and ansamycins are formed biosynthetically, how metabolites of the shikimate pathway are produced by micro-organisms and how a general ansamycin biosynthetic pathway has been formulated as a result of approaching rifamycin biosynthesis from an interdisciplinary perspective and a combination of microbiology, genetics, biochemistry, analytical chemistry and organic synthesis. ${ }^{[20]}$

Rifamycin and aromatic amino acid biosynthesis are closely related by the enzymatic condensation of phosphoenolpyruvate and erythrose-4-phosphate to 3-deoxy-D-arabinoheptulosonic acid-7-phosphate (DAHP). As this reaction is catalyzed by 3-deoxyD-arabinoheptulosonic acid 7-phosphate synthetase, the regulation of this enzyme in $N$. mediterranei was investigated. ${ }^{[21]}$

\subsection{Antitumor Compounds}

In the area of antitumor compounds, strain and process development towards improved production of the protein kinase C-inhibitor staurosporine led to the isolation of the mutant strain M14 of Streptomyces longisporoflavus R19, where the last reaction in staurosporin biosynthesis was blocked (Fig. 3), as well as to the isolation and characterization of the intermediate 3'-demethoxy-3'-hydroxy-staurosporine, which inhibited various protein kinase $\mathrm{C}$ subtypes more selectively. ${ }^{[22]}$ During screening for staurosporine metabolites, two original ways of producing the aglycon moiety K-252c of staurosporine, which also inhibits protein kinase $\mathrm{C}$, could be demonstrated: biosynthetic production of K-252c using S. longisporoflavus mutant M13 gave more 
Fig. 2. Microbial biosynthesis of rifamycins.
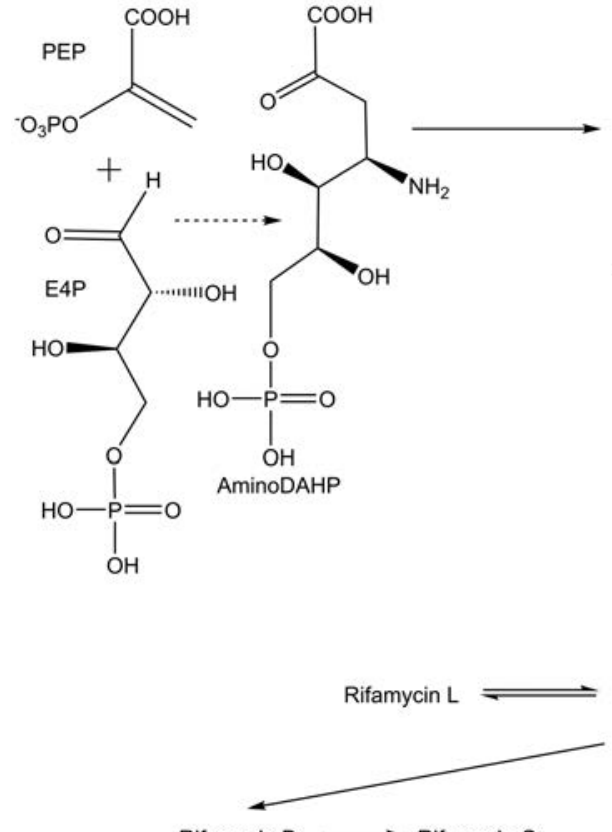

Rifamycin B Rifamycin O<smiles>N[C@H]1C[C@@](O)(C(=O)O)CC(=O)[C@H]1O</smiles><smiles>N[C@H]1CC([O-])=CC(=O)[C@@H]1O</smiles>

Aminodehydroquinic acid

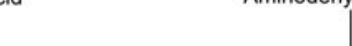

Proansamycin $\mathrm{X}$

Rifamycin W

i

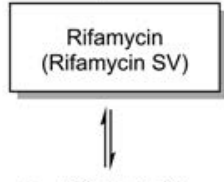

Rifamycin S

\subsection{Metabolites of Pharmaceuticals}

As selective chemical methods for the preparation of specific modification of complex molecules may be challenging, microbial synthesis is an alternative option. The often complex structure of pharmaceuticals and the introduction of even more complexity by metabolism makes therefore microbial synthesis an attractive approach for a selective and environmentally favorable modification of pharmaceuticals to the corresponding drug metabolites. As sufficient quantities of metabolites of pharmaceuticals are required for studying pharmacokinetics, absorption, metabolism, excretion and toxicology of new drugs, ${ }^{[24]}$ developing synthetic methodologies for making them available in pure form in a timely manner is essential in the workflow to market for all novel molecular entities. A selection of metabolites and their preparation (Fig. 4) by newly developed microbial biotransformations is described in the following.

Microbial epoxidation of carbamazepine, the active pharmaceutical ingredient (API) of antiepileptics, has been achieved by screening eleven bacterial and ten fungal strains, from which the strain Streptomyces violascens ATCC 31560 came out as being the most suitable for preparing 10,11-epoxy-carbamazepine.[25] Microbial hydroxylation of 10,11-dihydrocarbamazepine to 10,11-dihydro-10-hydroxycarbamazepine has been achieved by ten Streptomyces strains, with four $S$. griseus and one $S$. violascens strain being the most active microbes. ${ }^{[25]}$ A microbial process for the $13 \beta$-hydroxylation or 14,15-epoxidation of milbemycins has been patented. ${ }^{[26]}$ As the chemical hydroxylation of dianilinophthalimide CGP52411, which inhibits the epidermal growth factor receptor (EGF-R) protein tyrosine kinase in a potent and selective way, was complicated and not easily scalable, a microbial screening was performed to replace the chemical by a microbial hydroxylation, resulting in a simple one-step method for preparing the monohydroxylated metabolite of 4,5-dianilinophthalimide using Cunninghamella elegans DSM 1908 as the most suitable biocatalyst.[27] In the case of CGP 62706, another inhibitor of EGF-R protein tyrosine kinase, no detectable amounts of its metabolite, hydroxylated at the indole moiety were found, but instead 4"-O-methylglucoside was formed with Beauveria bassiana strains DSM 875 and DSM 1344, which hydroxylated CGP 62706 at the 4'-C position followed by glucosylation and enabled the preparation of the glucosylated metabolite in 5-11\% and $7-15 \%$ yield, respectively. ${ }^{[28]}$ The free 4'-hydroxylated me-

Fig. 3. Staurosporin biosynthetic pathway. 


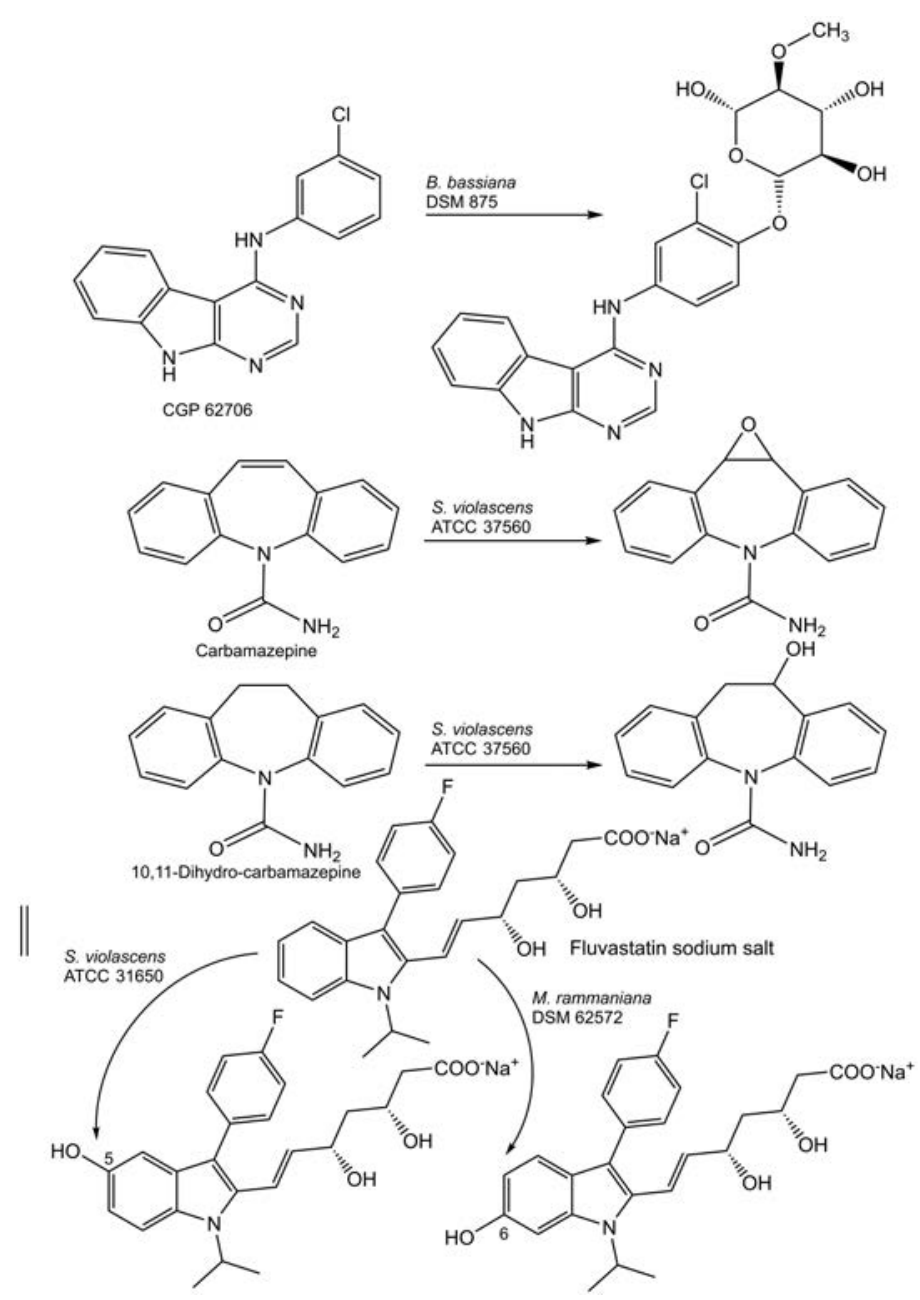

Fig. 4. Selected metabolites of pharmaceuticals and their preparation by microbial biotransformations.

tabolite can then be easily accessed by hydrolyzing the glycoside. The correlation between human, mammalian and microbial oxidative drug metabolism is of special interest in the development of reaction platforms for the generation of drug metabolites by biocatalytic selective oxidations. ${ }^{[29]}$ Suitable microbial strains, recombinant human cytochrome $\mathrm{P} 450$ systems and cytochrome P450 isozymes have been attractive biocatalysts to gain synthetic access to specific drug metabolites by oxidative reactions. ${ }^{[30]}$

In the treatment of hypercholesterolemia, statins have become the most commonly prescribed drugs for lowering serum cholesterol content. The preparation of human statin metabolites has therefore been an important task in the development of the various statins. In the development of the drug fluvastatin, the preparation of the major human metabolites 5-hydroxyfluvastatin and 6-hydroxy-fluvastatin was evaluated. Selective microbial oxidation of the drug to 6-hydroxyfluvastatin has been achieved using Mortierella rammaniana DSM 62752, yielding several hundred milligrams of product by cultivation in shake flasks and grams by using a Wave bioreactor for cultivation. ${ }^{[31]}$ A high conversion of $>95 \%$ was obtained utilizing a fluvastatin concentration of $0.1 \mathrm{~g}$ per liter at $400 \mathrm{~mL}$ scale when using shake flasks for cultivation and the same high conversion was also achieved in a Wave bioreactor at the higher final fluvastatin concentration of $0.4 \mathrm{~g}$ per liter at $22 \mathrm{~L} \mathrm{scale.}{ }^{[31]}$ The other major human metabolite 5-hydroxyfluvastatin could be prepared by microbial oxidation of fluvastatin using shake flask cultivation of Streptomyces violascens ATCC 31560 , whereby glucose was checked for complete consumption before fluvastatin addition and the $\mathrm{pH}$ had to be stabilized after fluvastatin addition. ${ }^{[31]}$ Since $S$. violascens produced both the 5- and the 6-hydroxylated fluvastatin metabolite, preparative liquid chromatography on reversed phase was performed and 5-hydroxyfluvastatin was obtained in multi-milligram amounts and much lower yield. [31]

The moderate metabolic stability of an antagonist of a metabotropic glutamate receptor subtype gave rise to detailed studies of its major human metabolites, whereby a range of various metabolites was prepared for elucidating the structure and biological activity of these drug metabolites. ${ }^{[32]}$ The most suitable isoforms out of fourteen recombinant human enzymes were identified, namely cytochrome P450 enzyme isoforms which were expressed together with P450 reductase in Escherichia coli. E. coli whole-cell biotransformations with cytochrome P450 isoforms 1A1, 1A2 and $3 \mathrm{~A} 4$ were performed at $2.5 \mathrm{~L}$ scale, metabolites were then extracted using XAD-16 resin and preparative liquid chromatography on reversed phase was used to access the metabolites in subto multi-milligram amounts. ${ }^{[32]}$ The isolated metabolites enabled detailed structural identification beyond the proposals from LCMS analysis and can be used as standards for biological activity tests, pharmacokinetic and toxicity studies.

\subsection{Biobased Chemicals}

In the production of methanol, a hypothetical direct microbial oxidation of methane, available from natural gas and biogas feedstocks, was discussed as a possible alternative energy saving process to the chemical process of the indirect conversion of methane into methanol. ${ }^{[33]}$ The way that biotechnology can provide efficient synthetic routes from biobased resources to chemicals and thereby contribute to sustainable development became another favorite topic. [34]

\section{Microbial Biodegradation}

Having always been interested very much in environmental aspects, it is no wonder that Oreste Ghisalba also investigated how chemical waste could be degraded by microbial methods as an alternative to waste disposal by physical means. ${ }^{[35]}$ Cultures of specialized methylotrophs were investigated for the microbial treatment of typical mother liquor waste coming from largescale chemical production and serving as model waste. ${ }^{[36,37]}$ From the liquid waste of a methylation process, which contained monomethylsulfate, and a mother liquor which contained $N, N$ dimethylformamide, novel Pseudomonas and Hyphomicrobium bacteria were enriched, isolated and characterized, while from the liquid waste of a dealkylation process which contained trimethylethylammonium chloride, Pseudomonas species were enriched, isolated and characterized. ${ }^{[36-38]}$ Pathways for the enzymatic degradation of monomethylsulfate, $N, N$-dimethylformamide and trimethylethylammonium chloride have been proposed and in the cell-free extracts novel enzymes have been discovered. As the biodegradation of selected C1- and C2-compounds used as organic solvents in synthetic processes, such as acetamide, acetonitrile or ethanol, attracted a lot of interest, the substrate scope of these specialized methylotrophs were investigated. Their potential use in the microbial degradation of waste was evaluated in pilot fermentations with pure substrates and model waste. ${ }^{[38]}$ The novel Pseudomonas and Hyphomicrobium microorganisms, the corresponding biomass containing proteins and a wastewater purification process using microorganisms for the biodegradation of methyl-group containing compounds have been patented. ${ }^{[39,40]} \mathrm{An}$ interdisciplinary research project at Ciba-Geigy aimed at making use of the various opportunities for enzymes and microorganisms in an integrated manner.[41] The value of enriching and isolating microorganisms with desired properties from suitable environments was demonstrated by the characterization of fourteen new methylotrophs capable of DMF biodegradation, although the ability to use DMF as sole energy, carbon and nitrogen source was not known to be common among methylotrophs, since the $>30$ tested methylotrophs from strain collections which were able to degrade 
methanol and methylamine, could not utilize DMF. ${ }^{[42]}$ Total biodegradation of DMF was achieved by all strains, identified as Pseudomonas sp., whereby only ammonium ions were observed and organic intermediates did not accumulate. ${ }^{[2]}$ The biodegradation route for the strains isolated from a sewage sludge and a lake sediment started with the $\mathrm{N}, \mathrm{N}$-dimethylformamidase-catalyzed cleavage of DMF into formate and dimethylamine, while this enzyme was not present in the strains isolated from a mud pond. ${ }^{[42]} \mathrm{A}$ whole range of related methyl-containing compounds were demonstrated to be utilized by these strains. ${ }^{[42]}$ Biomass production in waste biodegradation was also highly interesting within an integrated program in the search for useful novel biocatalysts, which can be applied for bioanalysis and biosensors, for regio-, stereo- and/or enantioselective synthesis and for whole-cell biotransformations. ${ }^{[41]}$ The utilization of microbes and their biocatalysts in microbial biodegradation, biosensing and environmental control has been bridged very nicely to, at first sight, very different applications in organic synthesis, but at a molecular level connected very much by the search and understanding of the underlying reactions catalyzed by the biocatalysts. ${ }^{[43]}$ Within this search three different sectors of screening were important for developing a bioprocess, from screening for biocatalysts (microbial whole cells, enzymes) having the desired properties to the search for optimal cell growth conditions and for optimal conditions to produce highly active biocatalysts, which worked best when the desired enzyme is essential for cell growth, as well as for the biocatalytic reaction. ${ }^{[41]}$ The specialized methylotrophs, which were originally isolated to replace physical degradation of chemical waste by specific biodegradation, were excellent sources of novel enzymes such as methylsulfatase, $\mathrm{N}, \mathrm{N}$-dimethylformamidase, esterase and methanol dehydrogenase. ${ }^{[41]}$

In addition to biodegradation, analytical applications were also investigated. The construction of a biosensor, which consisted of a combined glass electrode and the physically entrapped Hyphomicrobium MS 219 bacterium which degrades methylsulfate, enabled the detection of methylsulfate at concentrations between $10^{-3} \mathrm{M}$ and $1 \mathrm{M}$ with response times of 5 minutes in the linear range. ${ }^{[44]}$

The immobilized $N, N$-dimethylformamidase was used for dimethylformamide determination in waste water and process effluents within the concentration range from $0.05-15 \mathrm{mM}$ dimethylformamide using flow injection analysis, and can also be used to control the dimethylformamide concentration permanently. ${ }^{[45]}$

A wide range of organophosphorus compounds, which usually occur as phosphate esters and have been applied extensively, can be degraded by bacteria. ${ }^{[46]}$

\section{Microbial Enzymes}

With his deep interest in microbial diversity as well as chemistry, Oreste Ghisalba very much liked to search for microbes capable of performing specific biotransformations which he used for synthetic or analytical purposes and, therefore, he always emphasized the power of classical screening approaches, such as those successfully demonstrated by pioneering discoveries in Japan. The work on microbial biodegradation and methylotrophic bacteria was the starting point for the isolation of various enzymes which have been characterized biochemically.

The Pseudomonas DMF 3/3 enzyme, which catalyzes the hydrolysis of $N, N$-dimethylformamide (DMF), was purified and characterized as a $250 \mathrm{kDa}$ protein consisting of two smaller and two larger subunits and as an iron-containing amidohydrolase to which the name $N, N$-dimethylformamidase was given, in short DMFase. ${ }^{[47]}$ The substrate scope was found to be rather narrow beside DMF and $N$-ethyl-formamide, with $N$-methylformamide and other amides with substituted aliphatic short chains being preferential substrates. Other substituted amides such as $N, N$ diethylformamide as well as acetamide, acrylamide, butyramide, formamide, prolinamide were found to be hydrolyzed at significantly lower rates. The isoelectric point of DMFase is 7.7. The enzyme activity was optimal at a pH of 5 to 6 and at $40{ }^{\circ} \mathrm{C}$, while stability was optimal at $\mathrm{pH}>7.5$ and at temperatures $<20^{\circ} \mathrm{C}$. DMFase obeys Michaelis-Menten kinetics and a Lineweaver-Burk plot led to a $\mathrm{K}_{\mathrm{M}}$ of $13.8 \mathrm{mM}$ and $\mathrm{V}_{\max }$ value of $1.89 \mathrm{U} / \mathrm{mg}$ for DMF. ${ }^{[47]}$

An NAD(P)-independent methanol dehydrogenase with a broad substrate scope of primary alcohols, secondary alcohols, aliphatic aldehydes was characterized as a $118 \mathrm{kDa}$ protein consisting of two subunits and 9.7 as isoelectric point. ${ }^{[48]}$ This methanol dehydrogenase was activated by ammonium ions and showed optimal activity at $\mathrm{pH}$ 9.5. ${ }^{[48]}$

A carboxylesterase from Nocardia mediterranei was purified and shown to catalyze preferentially the hydrolysis of acetylesters, while propionylesters were hydrolyzed very slowly and no hydrolysis was observed with butyryl esters. ${ }^{[49]} \mathrm{pH} 7.5$ and $35^{\circ} \mathrm{C}$ was found to be optimal for this carboxylesterase activity. ${ }^{[49]}$

Various esterases and lipases from microbial sources have been found to catalyze the enantioselective hydrolysis of prochiral 2-benzylglyceroldiacetate to the chiral monoacetate, whereby the enzymes from Aspergillus fumigatus and Mucor javanicus gave the $(S)$-enantiomer with $75 \%$ ee and a purified lipase/esterase from Pseudomonas fluorescens gave the $(R)$-enantiomer with $96 \%$ ee. ${ }^{[50]}$

Arthrobacter aurescens AcR5b, isolated by enrichment culture from a wet haystack and utilizing as sole carbon source $(R)$ $N$-acetyl-1-phenylethylamine, was shown to possess an enantioselective deacetylating enzyme, which could $(R)$-specifically deacylate several derivatives of $N$-acetyl-1-phenylethylamine. [51] After optimized production and purification, the amidohydrolase was obtained with increased specific activity and $67 \%$ recovery. $\mathrm{pH} 8$ and $50{ }^{\circ} \mathrm{C}$ were the optimal conditions for the activity of this $220 \mathrm{kDa}$-enzyme consisting of two subunits of $16 \mathrm{kDa}$ and $89 \mathrm{kDa}$ and the amidohydrolase was stable up to $30^{\circ} \mathrm{C}$ and at $\mathrm{pH}$ 7-9.[51]

Novel acylases have been identified that do not show lipase- or esterase activity and are able to catalyze the stereoselective hydrolysis of racemic acylamides carrying an aliphatic acyl residue and are not derivatives of natural amino acids..$^{[52]}$

A new purification procedure was developed for the first preparation of dihydrodipicolinate (DHDPS) from a plant source, Pisum sativum, whereby in addition to conventional chromatographic steps a new affinity chromatography method was the key step. ${ }^{[53]}$ It was based on a stationary phase prepared by the immobilization of the competitive DHDPS-inhibitor $(S)$-aminoethyl-Lcysteine on Eupergit $\mathrm{C}$ and thus on selective interactions between the enzyme and its immobilized inhibitor ${ }^{[47]}$ and the affinity chromatography step required a compromise between enzyme binding and enzyme stability. The obtained highly active DHDPS was shown to be homogeneous by SDS-PAGE and the $127 \mathrm{kDa}$ protein, consisting of three identical $43 \mathrm{kDa}$ subunits, was characterized biochemically. ${ }^{[53]}$

Earlier work with mutants M13 and M14 of a staurosporineoverproducing Streptomyces longisporoflavus strain indicated an enzymatic methylation of the 3'-hydroxy group as last reaction in the biosynthetic pathway to staurosporin. ${ }^{[22,23]}$ The secretion of 3'-demethoxy-3'-hydroxy-staurosporine (CGP 58546) by the M14 block mutant strain enabled the preparation of this essential enzyme substrate for the investigation of this enzymatic methylation reaction of the staurosporine pathway in Streptomyces longisporoflavus. Enzyme activities of a 3'-demethoxy-3'-hydroxystaurosporine $O$-methyl transferase could be demonstrated in crude cell extracts of $S$. longisporoflavus strains as well as for the partially purified enzyme by radioactive enzyme assays using ${ }^{14} \mathrm{C}$-labelled $S$-adenosyl-methionine, while in crude cell extracts of the block mutant M14, which produces 3'-demethoxy-3'-hydroxystaurosporine, no methyltransferase activity could be detected.[54] Challenges for the application of this enzyme include strong inhi- 
bition of the methyl-transferase by $S$-adenosyl-homocysteine and stability issues of the partially purified enzyme during concentration and storage at $4{ }^{\circ} \mathrm{C}$.

A highly active phosphodiesterase from Serratia marcescens, obtained by preparing a crude cell-free extract, heat treatment and subsequent gel filtration, was demonstrated to have a broad substrate scope, optimal activity between $\mathrm{pH} 6.8$ and 9.4 and in the temperature range of $60-65^{\circ} \mathrm{C}$. ${ }^{55-57]}$

A lyase, which catalyzes the nitrogen-carbon cleavage reaction from peptidylhydroxyglycine to peptidylamides and is of interest for the second reaction of C-terminal amidation of peptides, was purified from Xenopus laevis skin and structural investigations of the amino acid and encoding nucleotide sequences of the highly purified peptidylhydroxyglycine $\mathrm{N}-\mathrm{C}$ lyase were performed.[58]

\section{Enzymes in Organic Synthesis}

The fascination of the capabilities and versatility of enzymes as catalysts privileged by nature and by the protecting group-free synthetic reactions catalyzed by them led Oreste Ghisalba to work on the integration of biocatalysts, whether as whole cells, cell-free extracts or isolated enzymes, into organic synthesis (Fig. 5) and synthetic medicinal chemistry. ${ }^{[41]}$

As microorganisms used in waste degradation processes can be produced at low cost they represent an attractive biobased source for biocatalysts, especially hydrolases. ${ }^{[59]}$ Methylotrophic bacteria isolated from the environment contain esterases, which were investigated either as whole cells or purified enzymes, for their use in efficient enzyme-catalyzed resolution methods of racemic mixtures ${ }^{[60,61]}$ to the two chiral building blocks $(2 R)$ indoline-2-carboxylic acid and $(2 R, 4 R)$-2,4-dimethylglutaric

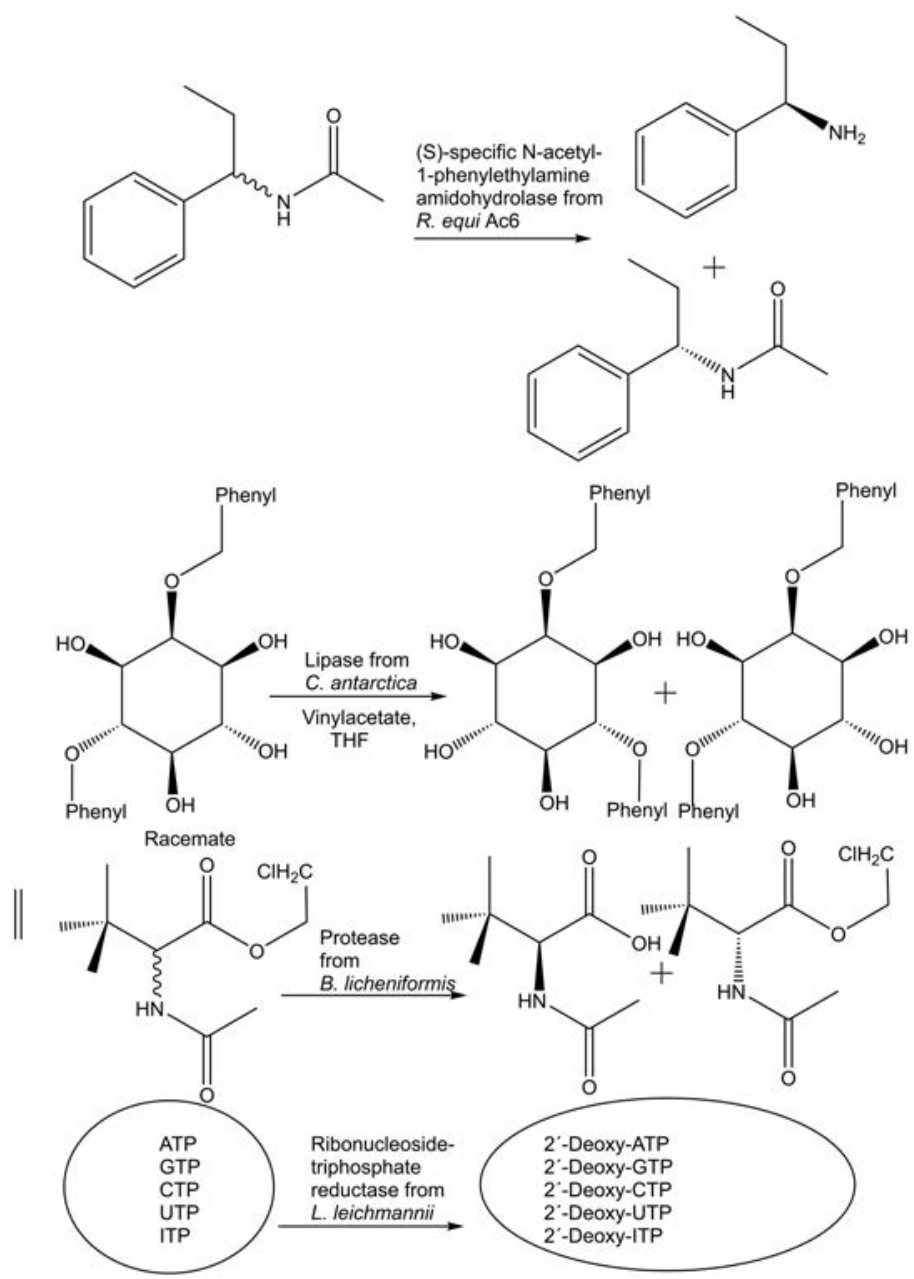

Fig. 5. Integration of biocatalysts into organic synthesis - selected examples. acid monoethylester, which are of interest in the preparation of an inhibitor of the angiotensin converting enzyme. The esterasecatalyzed enantioselective resolution of racemic 2,4-dimethylglutaric acid diethylester was investigated in an extensive screening with 100 microorganisms to obtain the key chiral building block $(2 R, 4 R)$-2,4-dimethylglutaric acid monoethylester.[60] Streptomyces R 1186 was found to be the most suitable strain, but unfortunately with only moderate enantioselectivity and not usable due to further degradation of the primary hydrolysis product. Although enantioselectivity could be increased to an $\mathrm{E}=17.5$ by using the racemic methylester and Pseudomonas DMF 5/8 for the enantioselective hydrolysis, partial product hydrolysis still limits the synthetic applications. The enantioselective hydrolysis of the racemate of $\mathrm{N}$-acetylindoline-2-carboxylic acid methyl ester has been demonstrated to be catalyzed by both whole cells as well as isolated esterase of the methanol utilizer isolate EE 2010 and afforded the (2R)- $N$-acetylindoline-2-carboxylic acid with $98 \%$ ee, but a lower yield was obtained when isolated esterase was used.[61] The $(2 S)$-enantiomer was obtained with $90 \%$ ee by using isolated esterase from Pseudomonas DMF 5/85, whereby the addition of $10 \%$ acetone led to $92 \%$ ee but decreased the yield. ${ }^{[61]}$

Crude pig pancreas lipase was fractionated by chromatography on Sephadex G75 and the fractions were tested for the enantioselective hydrolysis of the prochiral 2-substituted 1,3-propandiol diacetates, because purified lipase from pig pancreas did not catalyze hydrolysis and the commercially available crude pig pancreas lipase which catalyzed hydrolysis contained both lipases and carboxylesterases. ${ }^{62]}$ The protein pool 1, which contained fractions of higher molecular weights, gave the best results with $>95 \%$ ee when 1-butenyl- and phenyl-substituents were used and this protein fraction was then immobilized on Eupergit $C$ for preparative work. ${ }^{[58]} \mathrm{A}$ different purification procedure of the raw enzyme was developed for the transesterification in organic solvent, for which the crude pig pancreas lipase solution (in phosphate buffer at $\mathrm{pH}$ 8) was fractionated with acetone and the precipitated proteins were directly adsorbed on Hyflo Super Cel, which could then be applied in organic media using methylacetate as the acyl donor as well as a solvent. ${ }^{[62]}$ This enzyme preparation enabled the enantioselective acylation of the 2-substituted 1,3-propandiols with $>90 \%$ ee and thus providing easy access to both enantiomers of the corresponding monoacetates. ${ }^{[62,63]}$ Pseudomonas fluorescens lipase enabled solvent-free access to (S)-3-O-acyl-2-O-benzylglycerols with $>98 \%$ ee and high yield. ${ }^{[64]}$

Both 2-amino-3,3-dimethylbutyric acid enantiomers (D- and L-tert.-leucine) have been prepared by protease-catalyzed enantioselective hydrolysis of a racemic ester of 2-amino-3,3-dimethylbutyric acid. ${ }^{[65,66]}$ Careful screening was performed for the most suitable type of ester and the most active protease catalyzing the corresponding enantioselective hydrolysis. ${ }^{[65,66]}$ Enantiomerically pure D-2-amino-3,3-dimethylbutyric acid was produced by hydrolyzing racemic $\mathrm{N}$-acetyl-2-amino-3,3-dimethylbutyric acid chloroethylester using a commercially available protease (Alcalase) from Bacillus licheniformis and after 50\% conversion. ${ }^{[66]}$ Due to its broad substrate specificity the same enzyme has also been useful for preparing pure enantiomers of monomethoxy-, dimethoxy- and trimethoxy-substituted phenylalanines, which were highly suitable as synthons in the preparation of new and better proteasome inhibitors as well as for combinatorial approaches in drug discovery. In the same way $(R)$ - or $(S)$-enantiomers of mono-, di- or tri-substituted phenylalanines were obtained by hydrolyzing enantioselectively the $N$-acetyl protected amino acid esters, separation of the $(S)$ - $N$-acetyl amino acid $/(R)-N$-acetyl amino acid ester mixture and acidic cleavage.[67]

As chiral amines represent an important group of chiral building blocks in drug discovery and the manufacturing of pharmaceuticals, screening for selective hydrolysis of racemic amides led to the discovery of novel highly enantioselective amidohydrolases, which 
were then broadly investigated for preparative applications. ${ }^{[68-70]}$ The synthesis of chiral arylalkylamines with high enantiomeric purity was achieved by the use of novel amidohydrolases. ${ }^{[65]}$

The interest in the role of inositol phosphates as messengers and signaling molecules in cellular regulation created the need for simple and easy synthetic routes to inositol phosphates at preparative scale. Therefore a whole range of enantioselective discrimination of enantiomers as well as enantioselective desymmetrizations catalyzed by enzymes have been investigated. Valuable inositol phosphates, including fluorescently labelled inositol phosphates, have been prepared by chemoenzymatic synthesis using commercially available lipases. ${ }^{[65]}$

As studies of the brain enzyme inositol monophosphatase and its inhibitors required an effective synthesis of D-myo-inositol1-phosphate, a new chemoenzymatic route was developed starting from myo-inositol and using a lipase-catalyzed enzymatic desymmetrization of the meso-compound 4,6-di- $O$-benzyl-myo-inositol as key step. ${ }^{[71]}$ This was successfully achieved by enantioselective acylation using a Pseudomonas sp. lipase and vinylacetate as irreversible acyl donor and solvent, which enable the selective enzymatic acetylation of the 1-position leading to the 1D-enantiomer of the 1-O-acetylated 4,6-di- $O$-benzyl-myo-inositol.[71]

A new and straightforward enzyme-catalyzed racemate resolution has been developed to provide 2,6-di-O-benzyl-myo-inositol enantiomers as intermediates in a simplified synthesis of enantiomerically pure D-myo-inositol 1,3,4,5-tetrakisphosphate and L-myo-inositol 1,3,4,5-tetrakisphosphate. ${ }^{[72]}$ Regio- and enantioselective acylation in the 5-position of racemic 2,6-di- $O$-benzylmyo-inositol was screened using commercially available lipases and the irreversible acetyl donor vinylacetate and clearly showed the lipase from Candida antarctica to be the best biocatalyst. ${ }^{[72]}$ Thereby the regio- and enantioselective acylation in the 5-position was achieved for the L-enantiomer only, thus giving the $1 \mathrm{~L}-5-O$ acetyl-2,6-di- $O$-benzyl-myo-inositol with $>99 \%$ ee. ${ }^{\text {[72] }}$ The natural D-enantiomer and the unnatural L-enantiomer of myo-inositol 1,3,4,5-tetrakisphosphate were finally synthesized as tetrapotassium salts by the chemical reaction sequence of phosphorylation, oxidation and deprotection of the D- and L-enantiomers of 2,6-di$O$-benzyl-myo-inositol, respectively. ${ }^{[72]}$

Selective enzymatic deoxygenations provide great value because of a unique and direct access to deoxy-compounds from their corresponding oxygenated starting materials, such as in the case of the enzymatic 2'-deoxygenation of ribonucleoside 5'-triphosphates to their corresponding 2'-deoxyribonucleoside 5'-triphosphates, catalyzed by ribonucleoside triphosphate reductase, because other strategies like chemical synthesis or hydrolysis of cellular DNA have not been considered viable when it comes to industrial production. ${ }^{[73]}$ The 5'-deoxy-adenosylcobalamin-dependent ribonucleoside triphosphate reductase of Lactobacillus leichmannii was selected as the most suitable enzyme for preparative purposes due to its known reaction mechanism, monomeric structure and a recombinant strain available for expression of the enzyme. ${ }^{[73]}$ Ribonucleoside triphosphate reductase has been expressed in E. coli HB101 pSQUIRE, purified first by sonication, ammonium sulfate fractionation, hydroxyapatite chromatography and ultrafiltration, ${ }^{[73]}$ later by liquid-liquid extraction. ${ }^{[74]}$ The biochemical characterization of the ribonucleoside triphosphate reductase showed that the ribonucleoside-5'-triphosphates are good substrates, with similar reaction kinetics in the 2'-reduction of the corresponding 5'-triphosphates of adenosine, guanosine, cytosine, uridine and inosine catalyzed by ribonucleoside triphosphate reductase, with full conversion and no substrate inhibition. ${ }^{[73,74]}$

\section{Industrial Biotransformations}

Oreste Ghisalba clearly analyzed the key aspects needed to make biotransformations a commercial success. He emphasized environmental issues in chemistry; rendered non-selective reac- tion steps more resource-efficient by avoiding protecting group strategies and concluded that it is essential to have scientists from chemistry and biology work together. In this way, routes could be selected and priorites set to discover novel enzymes ready to be used in the laboratory and introducing novel process engineering. ${ }^{[75-93]}$ By analyzing mutual misunderstandings between chemists and biologists, Oreste Ghisalba advocated common understanding between scientists in the fields of chemistry and biology as a prerequisite to set the course to the future and the priorities for novel biotransformations and biocatalysts. ${ }^{[75-87]}$ Industrial scale for biotransformations can greatly vary from small scale to the very large scale, depending on the requirements for the total amount of the product needed. Beside large-scale production processes also industrial biotransformations at small scale can provide key contributions to the value creation chain. A selection of industrial biotransformations to various product classes is described in the following (Fig. 6).

As direct one-step biocatalytic phosphorylation processes, avoiding the introduction and removal of protecting groups, have several advantages over chemical phosphorylation methodologies, D-ribulose-5-phosphate was synthesized from D-ribulose by D-ribulokinase-catalyzed phosphorylation in the 5-position, using the isolated enzyme from Klebsiella pneumoniae. ${ }^{[75]}$ The use of adenosine 5'-triphosphate (ATP) as phosphoryl donor stoichiometrically without regeneration was compared with the process where only catalytic amounts of ATP were used and regenerated with pyruvate kinase. ${ }^{[75]}$ Based on the determination of the kinetic parameters of both enzymes and performance calculations, both process options for the D-ribulokinase-catalyzed phosphorylation of D-ribulose were implemented in an enzyme membrane reactor to continuously produce D-ribulose-5-phosphate. ${ }^{[75]}$ Both production processes worked continuously for more than $200 \mathrm{~h}$ and 117
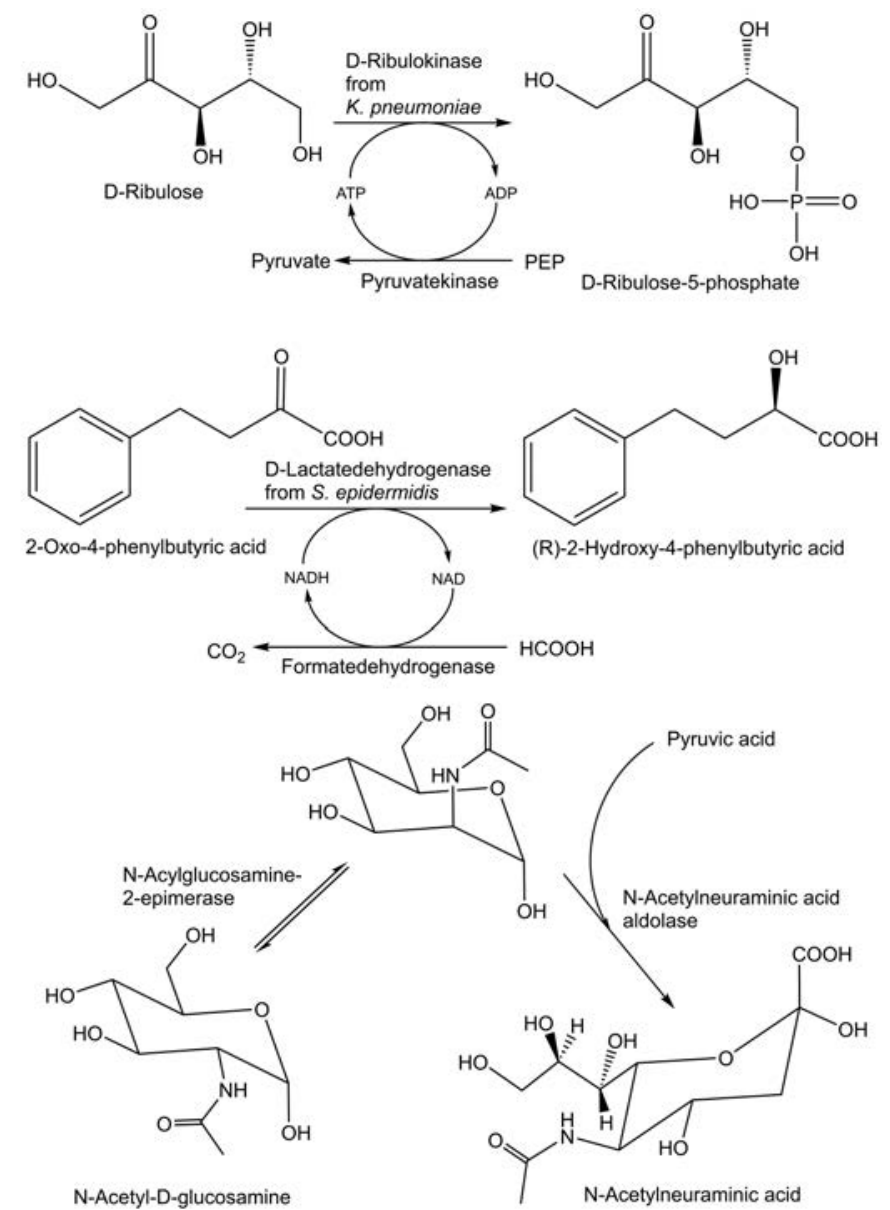

Fig. 6. Selected industrial biotransformations. 
grams of D-ribulose-5-phosphate per liter and per day were obtained in the process with ATP regeneration, while in the process without ATP-regeneration 103 grams of D-ribulose-5-phosphate per liter and per day were achieved.[75]

Another successful economic and scalable biotransformation was established to produce $N$-acetyl-neuraminic acid by coupling two subsequent enzyme-catalyzed reactions, thereby overcoming previous bottle-necks for its isolation from natural biological sources or for coupling chemical and enzymatic steps. ${ }^{[76-79]}$ The new process starts by epimerizing $N$-acetylglucosamine, catalyzed by $\mathrm{N}$-acetylglucosamine 2 -epimerase, to $\mathrm{N}$-acetylmannosamine, which is then directly coupled, without isolation of the intermediate, with pyruvic acid to the final product $N$-acetylneuraminic acid, catalyzed by $N$-acetylneuraminic acid aldolase. For the onepot conversion of the two enzymatic reaction steps in homogeneous solution an enzyme membrane reactor was selected, where a suitable ultrafiltration membrane retains the enzymes and is permeable only to the product and the substrates, which are fed into the reactor at a constant rate. The reaction conditions, such as $\mathrm{pH}$, temperature, enzyme concentration, activity and stability as well as residence time, for continuously operating the two coupled enzyme-catalyzed reaction steps in an enzyme membrane reactor were investigated in batch experiments and were based on kinetic and thermodynamic analyses. ${ }^{[76-79]}$ The investigation of the activation and inhibition of enzymes was another important aspect for setting up the reaction conditions, such as the addition of ATP and magnesium ions to the substrate solution, because it was needed for the activation of $N$-acetylglucosamine 2-epimerase and because it inhibited $N$-acetylneuraminic acid aldolase only very weakly. In order to save costs and time in product recovery and purification, the ratio of the pyruvic acid to the $N$-acetylneuraminic acid was kept at a smaller value in order to simplify $N$-acetylneuraminic acid purification by anion exchange chromatography. ${ }^{[76-79]}$ With this process, $109 \mathrm{~g} N$-acetylneuraminic acid were synthesized per liter and per day in continuous operation, with no observed decrease of conversion. ${ }^{[77]} \mathrm{By}$ simulating and optimizing reaction conditions further, enzymatic synthesis of $\mathrm{N}$-acetylneuraminic acid at multi-kilogram amounts for industrial applications resulted in an increased space-yield of $470 \mathrm{~g} / \mathrm{L}$ per day for the reaction and a sequence of anion exchange chromatography, concentration by reverse osmosis and lyophilization as downstream processing steps. ${ }^{[80]}$

The availability of $N$-acetylneuraminic acid reaction engineering was a key success factor for cytidine 5'-monophospho- $N$ acetyl-neuraminic acid production (CMP-NANA), which is very important as substrate for sialyltransferases and as sialyl-donor in enzymatic sialylations. ${ }^{[81-84]}$ As the synthesis of CMP-NANA required, in addition to the substrates $N$-acetyl-neuraminic acid and cytidine 5-triphosphate, sufficient quantities of the enzyme CMP-NANA synthetase, which up to that time has been prepared mainly from animal-derived sources and was therefore challenging to obtain reproducibly and in larger amounts, a screening for a suitable microbial enzyme was performed. From screening forty bacterial strains as producers of CMP-NANA synthetase Escherichia coli K-235 ATCC 13027, with no genetic modifications, was selected to produce $9200 \mathrm{U}$ of CMP-NANA synthetase in a fed-batch fermentation process at $200 \mathrm{~L}$ scale, sufficient for kilogram preparations of CMP-NANA. ${ }^{81,82]}$ Partial purification of the CMP-NANA synthetase, after crude extract preparation, focused on methods for achieving high enzyme recovery. CMPNANA synthetase preparations almost free of any side activity that would dephosphorylate CTP were obtained by precipitation with polyethylene glycol and batch adsorption to hydroxyapatite. ${ }^{[81,82}$ The CMP-NANA synthetase prepared by a simple one-step purification was shown to catalyze the formation of CMP-NANA with $>90 \%$ yield, but yields decreased significantly with increasing substrate concentrations and also systems involving the in situ generation of $\mathrm{N}$-acetylneuraminic acid or CTP gave much lower yields. ${ }^{[81,82]}$ Improved enzyme production was achieved by using E. coli variant K-235/CS1 and optimizing culture medium as well as cultivation conditions for enzyme production, leading to the production of $26500 \mathrm{U}$ highly active CMP-NANA synthetase by fed-batch fermentation at $230 \mathrm{~L}$ scale. ${ }^{[82,82]}$ Precipitation of the enzyme by $16 \%$ polyethyleneglycol 6000 was found to be the most effective method for obtaining with $100 \%$ recovery a CMPNANA synthetase preparation which was almost free of any CTP hydrolyzing activity. ${ }^{[83]}$ Stability investigations at $25{ }^{\circ} \mathrm{C}$ showed that the enzyme is most stable at neutral $\mathrm{pH}$ in phosphate buffer and that at temperatures of $40{ }^{\circ} \mathrm{C}$ and higher the enzyme loses activity rapidly, but that molar concentrations of sodium chloride, disodium hydrogen phosphate and glycerol can efficiently stabilize it. ${ }^{[83]}$ The application of this $E$. coli $\mathrm{K}-235$ CMP-NANA synthetase was successfully demonstrated by synthesizing CMPNANA, which was obtained in a batch reactor at about $10 \mathrm{mM}$ concentration with $87 \%$ conversion from CTP and without any CMP-NANA decomposing activity, but with small side activities which dephosphorylate CDP and CMP. ${ }^{[83]}$ A CMP-NANA synthetase which was further purified by hydrophobic interaction chromatography was used to continuously synthesize CMPNANA, using a pH-stat for the regulation of $\mathrm{pH} .{ }^{[82]}$ The synthesis of $111 \mathrm{~g} \mathrm{CMP-NANA}$ per liter and per day was achieved in this continuous process with $75 \%$ conversion and the products were purified by diafiltration, anion exchange chromatography and gel chromatography. ${ }^{[82]}$ To scale up the reaction, kinetic studies of the CMP-NANA synthetase reaction scheme were performed which included pyrophosphatase to convert pyrophosphate to phosphate in order to overcome the competitive enzyme inhibition of CMPNANA synthetase by pyrophosphate, but also taking into account the negative effect of chemical hydrolysis of the CMP-NANA product. ${ }^{\left[{ }^{84]}\right.}$ Based on an experimentally validated model of the kinetics of the reaction system and on a comparison of batch and continuous mode of synthesis, the batchwise production was more favorable due to the much more dominating effect of product inhibition. Therefore, the large-scale synthesis of CMP-NANA at multigram scale was performed in fed-batch employing short reaction times in order to minimize chemical hydrolysis of CMPNANA, while for the product isolation the use of nanofiltration membrane ROM 365 was important for product concentration both before and after Dowex anion exchange chromatography as well as for completely desalting the CMP-NANA solution after the anion exchange chromatography. ${ }^{[84]}$

As enantioselective reductions of keto group-containing compounds by biotransformations have led to the corresponding highly enantiopure $(R)$ - and $(S)$-hydroxy group-containing products, biocatalytic reductions have become an excellent synthetic platform technology of wide applicability. Since $(R)$-2-hydroxy4-phenylbutyric acid has been of much interest to manufacture angiotensin converting enzyme inhibitors and alpha-ketoacids are natural substrates of various dehydrogenases, the question was whether and which natural dehydrogenases would be suitable to catalyze this enantioselective reduction. Staphylococcus epidermidis D-lactate dehydrogenase was found to be most suitable for enantioselectively reducing 2-keto-4-phenylbutyric acid to the $(R)$-2-hydroxy acid. ${ }^{[85-88]}$ An efficient procedure to continuously produce $(R)$-2-hydroxy-4-phenylbutyric acid with $>99.8 \%$ ee was developed and optimized, using the NADH-dependent S. epidermidis D-lactate dehydrogenase together with the formate dehydrogenase cofactor regeneration system. ${ }^{\left[{ }^{[8-87]}\right.}$ As long-term enzyme stability is required for continuous production with constant and high quality in an enzyme membrane reactor, investigations of the involved enzymes have been performed, which demonstrated that both D-lactate dehydrogenase as well as formate dehydrogenase showed significant deactivation rates. ${ }^{[87]}$ The activity decrease could be minimized by the inclusion of mercaptoethanol or dithio- 
threitol in order to prevent the formation of undesired disulphide bridges and by the inclusion of chelators such as EDTA for the complexation of metals to prevent metal-catalyzed oxidation. ${ }^{[87]}$ The experimental determination of the kinetic parameters of both enzymes and a detailed model for the enzyme reaction system were the prerequisites for optimizing the reaction conditions in the enzyme membrane reactor. ${ }^{[87]}$ This enabled the production of 3.1 $\mathrm{kg}$ of $(R)$-2-hydroxy-4-phenylbutyric acid with an average productivity of $165 \mathrm{~g}$ of product per liter and per day when the residence time was 4.6 hours, but a higher productivity of $410 \mathrm{~g}$ of product per liter and per day was obtained when a shorter residence time of 1 hour and a $0.1 \mathrm{M}$ substrate concentration was selected in another production run. ${ }^{[87]}$ Enzyme activities were monitored during the production run and kept constant by further addition if required, but only small amounts of formate dehydrogenase and D-lactate dehydrogenase were consumed per kg of product produced. ${ }^{[86]}$ In an analogous way, the opposing $(S)$-enantiomer of 2-hydroxy4-phenylbutyric acid has been continuously produced with excellent enantiomeric excess in the enzyme membrane reactor by using the enantiocomplementary bovine heart L-lactate dehydrogenase and the formate/formate dehydrogenase-system to regenerate the cofactor NADH. ${ }^{[86]}$ The productivity of $1.6 \mathrm{~g}$ of product per liter and per day for this process was, however, much lower than for the process with the microbial D-lactate dehydrogenase. ${ }^{86]}$

Based on the biochemical characterization of ribonucleoside triphosphate reductase from Lactobacillus leichmannii, the use of high sodium acetate concentrations for the replacement of allosteric effectors and the identification of suitable artificial reducing agents to recycle the active center and reaction engineering, scalable preparative reductions of the ribonucleoside-5'-triphosphates were successfully achieved. ${ }^{[73]}$ For large-scale applications of the ribonucleoside triphosphate reductase the enzyme production and purification need to be simple and inexpensive and therefore a fast and simple liquid-liquid two-phase extraction procedure in one step was developed, whereby the ribonucleoside triphosphate reductase was obtained in $75 \%$ yield in the top phase. ${ }^{[74]}$

Technical aspects, companies, manufacturing facilities, largescale applications and corresponding products clearly indicate that industrial biotransformations have been making great advances and are continuing to provide key contributions to global sustainability. ${ }^{[89]}$ Although a great majority of industrial biotransformations which are relevant to the pharmaceutical industry are related to biocatalytic enantioselective reactions, an increasing need was expressed for biocatalytic regioselective reactions, such as selective hydrolytic cleavage of one of several ester groups, selective ester formation of only one of multiple carboxyl-groups, the selective reduction of one particular group among several carbonyl functional groups, the synthesis of glycoconjugates or the selective modification of peptides and proteins. ${ }^{[90]}$

As pharmaceuticals, nutrients or other compounds entering human metabolism are subject to biotransformations by the enzymes of human and microbial cellular systems, the corresponding metabolites resulting from these biotransformations are routine companions of the human ecosystems even without obtaining any attention, but can be highly important and relevant for the health and disease of numerous groups of people. In the area of pharmaceuticals, an adequate molecular understanding of the drug metabolites and the biotransformations responsible for their formation is of key importance for the corresponding industry developing the new molecular entities for the treatment of disease. During the course of the different phases of drug discovery and development, for tailoring novel therapeutic approaches to diagnostic outcomes and towards a truly molecular medicine, an adequate molecular understanding of the drug metabolites and the biotransformations responsible for their formation is a necessity. As therefore selective synthetic procedures are needed for the preparation of defined and pure metabolites of pharmaceuticals, although in much smaller amounts, industrial biotransformations have become established as essential synthetic methodology, as already described for a number of successful preparations of metabolites of pharmaceuticals by whole cell systems in Section 2. As whole cell biotransformations of compounds with various functional groups may lead to bottlenecks in the transport into or out of the cells and/or undesired side reactions due to the many different enzymes present in whole cells, biotransformations using isolated enzymes, from crude extracts to highly purified enzymes, provide another great opportunity for not only manufacturing metabolites of pharmaceuticals, but also for contributing to an increased understanding of the drug-metabolizing enzymes. In order to achieve these goals, the development and production of microbial[91] and human enzymes ${ }^{[92]}$ that are well-defined for the intended enzyme function, devoid of any interfering side activities and are ready to be applied to the enzymatic synthesis of adequate amounts of drug metabolites in a timely manner is essential, but the use of crude enzymes as inexpensive and easily available biocatalysts for the biotransformation of the drug has also been established as a successful approach for rapidly accessing drug metabolites.

Glucuronidation of pharmaceuticals, which is part of a major detoxification and elimination pathway, is a biotransformation catalyzed by uridine-5'-diphospho-glucuronyl-transferases and is of two-fold interest. The preparation of larger amounts of both labelled and unlabeled glucuronides of pharmaceuticals, which have a higher molecular weight and may be more polar than the pharmaceuticals themselves, is needed as drug metabolites for drug metabolism, safety and toxicity studies for the reasons mentioned before. Another line of interest for manufacturing the conjugate of a pharmaceutical with $\beta$-D-glucuronic acid comes from an approach aimed at reducing the overall toxicity of the pharmaceutical by taking advantage of the reduced toxicity of the glucuronide of the drug and using it as a prodrug, e.g. in an antibody-prodrug conjugate to direct it to the target tissue, where the pharmaceuticals would be selectively liberated by the intrinsic human enzyme $\beta$-D-glucuronidase.

The uridine-5'-diphospho-glucuronyl-transferase-containing supernatant from a crude homogenate of guinea pig liver was applied in the biocatalytic $O-\beta$-D-glucuronidation of the two compounds 6-(2-[(1-methylethyl) amino]propyl)pyridin-3-ol and N-[2-hydroxy-5-(1-hydroxy-2-((2-(4-methoxy-phenyl)-1methylethyl)amino) ethyl)phenyl]formamide, a selective $\beta_{2}$ sympathomimetic bronchodilator known as the active pharmaceutical ingredient formoterol in the treatment of asthma. ${ }^{[93]}$ Uridine5 '-diphospho- $\beta$-D-glucuronic acid was used as glucuronyl-donor directly without regeneration to continuously synthesize the glucuronides. ${ }^{[93]}$ Numerous reaction parameters had thereby to be considered for optimal operation, such as concentrations of substrate, glucuronyl-donor and protein, $\mathrm{pH}$, temperature and residence time. ${ }^{[93]}$ The glucuronidation catalyzed by glucuronyltransferase was carefully investigated versus the glucuronide hydrolysis catalyzed by $\beta$-glucuronidase, which was present in the supernatant of the crude homogenate of guinea pig liver. ${ }^{[93]}$ While the enzymatic glucuronidation of 6-(2-[(1-methylethyl) amino]propyl)pyridin3 -ol was achieved with constant $95 \%$ conversion, formoterol was found to be a less suitable substrate and a stable steady-state could not be reached, but nevertheless the continuous enzymatic synthesis has been achieved successfully for both $\beta$-D-glucuronides, which after isolation and purification with ion-exchange chromatography and HPLC have led, at the $100 \mathrm{mg}$ to $200 \mathrm{mg}$ scale, to the pure drug metabolites which were $O$ - $\beta$-D-glucuronidated selectively only at the phenolic oxygen of the drug. [93]

Human metabolism of mycophenolic acid, which has been of interest to the pharmaceutical industry as a drug for a long time due to its many antibacterial, antifungal, antiviral, antipsoriatic, antineoplastic and immuno-suppressive properties, 
showed the $O-\beta$-D-glucuronidation of mycophenolic acid at the phenolic oxygen to be the major metabolic pathway and to abolish thereby its pharmacological action. ${ }^{[94]}$ As then another glucuronidated metabolite of mycophenolic acid was discovered to be pharmacologically active, with similar efficiency as mycophenolic acid and with the $O-\beta$-D-glucuronidation of mycophenolic acid at the carboxylic oxygen, it was understandable that there was a request for the preparation of this interesting acylglucuronide of mycophenolic acid. ${ }^{[94]}$ From screening the supernatants of homogenates of a number of vertebrate livers, the one from horse liver came out as best biocatalyst with respect to the highest ratio of acylglucuronide versus $O$-glucuronide formed in the reaction, but this was only a ratio of about 1:1 and much less favorable ratios were observed for most of the other biocatalysts. Considering the higher stability of acylglucuronides at lower $\mathrm{pH}$ and optimizing the reaction parameters of $\mathrm{pH}$, temperature and uridine-5'-diphospho- $\beta$-D-glucuronic acid concentration, a 5.8-fold increase in the acylglucuronide: $O$-glucuronide-ratio and a 2.8-fold increase in the degree of conversion to the acylglucuronide was achieved. The optimized enzymatic reaction to produce the acylglucuronide of mycophenolic acid proceeded with $54 \%$ conversion to the acylglucuronide, which after adsorption on XAD16 resin and purification by HPLC was obtained in $>95 \%$ purity and $34 \%$ yield. The enzyme membrane reactor was in this application less favorable, because only $18 \%$ conversion was achieved and therefore more glucuronyl-donor is needed for a specific amount of product, thus leading to increased costs of raw materials. ${ }^{[94,95]}$

In the area of carbohydrate bioengineering of glycoproteins continuous enzymatic galactosylation of acceptor sites in a neoglycoprotein, ovalbumin and yeast invertase, which was deglycosylated with endoglycosidase $\mathrm{H}$, was achieved by using immobilized $\beta$-1,4-galactosyltransferase from pooled human milk and uridine-5'-diphospho-D-galactose as glycosyl-donor in a slurry reactor and ultrafiltration membranes of different molecular weight cutoff characteristics to obtain the galactosylated glycoprotein. ${ }^{[96]}$ Immobilization of the $\beta$-1,4-galactosyltransferase by both covalent and noncovalent affinity methods was demonstrated to be reproducible and to increase the enzyme stability considerably compared with the soluble enzyme. ${ }^{[96]}$ While the less costly covalent methods of immobilization to the cyanogenbromide-activated and the tresylchloride-activated sepharose were shown to give the best immobilization efficiencies but much lower immobilization yields and specific activities, the noncovalent methods of immobilization were shown to give only a low immobilization efficiency of $44-48 \%$ but more than twofold higher specific activities and immobilization yields. [96] With the use of a $100 \mathrm{kDa}$ molecular weight cutoff ultrafiltration membrane in the slurry reactor for the continuous galactosylation of ovalbumin, $55 \%$ of the acceptor on ovalbumin could be galactosylated, while the percentage of acceptor sites which could be galactosylated for the other two glycoproteins, in a setup with a $300 \mathrm{kDa}$ molecular weight cutoff ultrafiltration membrane in the slurry reactor, was lower, namely $35 \%$ for the endo $\mathrm{H}$-deglycosylated invertase and $25 \%$ for the neoglycoprotein. ${ }^{[96]}$

Biotransformations were also demonstrated to be valuable in the modification of the peptide part of biotechnological products. While a free $\mathrm{N}$-terminal threonine is characteristic for the protease inhibitor eglin from leech, recombinant eglin carries the $N$-terminal threonine as an $N$-acetylated form of the natural eglin. Because chemical methods for deacylating an $\mathrm{N}$-acetylated peptide consisting of 70 amino acids would also cleave the peptide chain nonselectively, screening for acylases, proteases and crude extracts from bacterial strains was performed in order to find enzymes accepting $N$-acetyl-eglin c as substrate for the selective deacetylation to the authentic eglin $\mathrm{c}$ or for the selective cleavage of a single peptide bond very close to the N-terminal threonine. ${ }^{[97]}$ Although no enzyme for the selective deacetylation of $\mathrm{N}$-acetyl-eglin c was found, several proteases which could cleave a peptide bond selectively were found, among which two proteases from $N$. mediterranei, named protease 1 and protease 2 , were shown to cleave near the $N$-terminal threonine between Phe(3)-Gly(4) and between Glu(2)-Phe(3).[97] The biochemical characterization of protease 1 showed that also an $\mathrm{N}$-acetyl-eglin c derivative was a substrate, with the Lys(8) and Lys(16) protected by the tert-butyloxycarbonyl-group (Boc-group) as well as the natural eglin c (Boc-Lys(8), Boc-Lys(16)-N-acetyl-eglin c). Immobilized protease 1 was then applied to the conversion of $N$-acetyl-eglin c to eglin c (4-70), to the biotransformation of Boc-Lys(8), Boc-Lys(16)-N-acetyl-eglin c to the Boc-Lys(8), Boc-Lys(16)-protected eglin c, which could then be converted by chemical reaction steps to natural eglin c or eglin c analogues and derivatives. ${ }^{[97]}$

This concludes the description of selected industrial biotransformations published by Oreste Ghisalba with coworkers and colleagues at small, medium and large scale, but he envisioned that the introduction of more bioprocesses and biobased considerations into industrial research and development will preserve and protect natural resources and ecosystems, minimize environmental pollution and repair environmental damage. ${ }^{[89]}$ Utilizing more renewable resources, using wisely and economically nonrenewable resources and protecting ecosystems through more biological processes and technological changes were considered to be achievable only if linked with economical, ecological, and social goals. ${ }^{[89]}$

\section{Teaching Activities}

In 1983 Oreste Ghisalba started his lectures on technical biomass utilization at ETH Zurich, which he continued until 2006. His lectures covered biological processes for biomass conversion, thereby dealing with microbiological basics such as organisms, growth and metabolism, biological methane formation, chemical versus biological conversion of biomass, plant production, microbial biomass, photosynthesis, carbon cycle, biological hydrogen production, hydrogen technology and liquid fuels from biomass. He completed in 1988 his habilitation in microbiology and in 1999 the University Basel appointed him as Professor for Biotechnology. Oreste Ghisalba contributed also to the teaching book 'Biotechnology for Beginners', edited by Arnold Demain, where the need for education and communication for biotechnological products and clean processes was emphasized to achieve market success. ${ }^{[98]}$ Being familiar with both the academic and industrial worlds Oreste Ghisalba also liked to slightly caricature actual situations of that time. He emphasized that invention should not be confused with innovation, the very different view and evaluation of innovation in catalysis by university and industry, the increasing gap between real industrial and purely academic needs and that new solutions to problems and applications would not necessarily emerge just from the accumulation of knowledge. ${ }^{[98]}$ Expanding the toolbox for biocatalysis was considered important but insufficient screening efforts were perceived on both sides, while the academic sector was diagnosed with too few efforts in bringing research results into innovative applications and too much emphasis on publishing. ${ }^{[98]}$ The teaching and the enzyme experiments in the microbiology block course fascinated students at university, while his position as head of a research group in industry provided an opportunity to the students to not only perform a diploma thesis but also a PhD thesis in industry, either initially at Ciba-Geigy or at Novartis after the merger with Sandoz. In 2011 Oreste Ghisalba retired and became Professor emeritus at the Biocenter. 


\section{SKB Activities}

From 1992-2015 Oreste Ghisalba was a member of the Swiss Coordination Committee for Biotechnology (SKB), which is also associated with the Swiss Academy of Engineering Sciences (SATW), contributing insightful, critical and valuable inputs to the spring and autumn meetings of SKB in Bern. He was instrumental for initiating and leading a number of great activities and initiatives, from a critical analysis, forward-looking perspectives and implementable strategies over team building and conceptualization to successful realization. He was a member of the 'Lateral Think Tank', a member of SATW Scientific Advisory Board and a co-organizer of the SATW Transferkolleg Industrial Biotechnology in 2007, a scheme highlighting research with market potential at an early stage and supporting knowhow transfer between academia and industry.

\subsection{Conceptual Work}

In 1990 Prof. Oreste Ghisalba and Prof. Horst Vogel produced an early insight study in biotechnology for the SKB and the Swiss Science Council (SWR), which for practical reasons consisted of two independent parts. ${ }^{[99,100]}$ Part 1 provided a detailed analysis of national and international biotechnology research programs of the most important industrialized countries and accompanied the parallel activities towards the formulation and initiation of a Swiss Biotechnology Program, which were in preparation by SKB and the Federal Office Bundesamt für Bildung und Wissenschaft (BBW). ${ }^{[99]}$ The concepts and strategies of public funding of biotechnology, which already existed in medium to long-term national research programs in a number of industrialized countries, were analyzed and the perspectives for the development of biotechnology as a key enabling technology in general and in its importance specifically to Switzerland were outlined. ${ }^{[99,100]}$

The biotechnology programs of Germany, France, Netherlands, Great Britain, the Scandinavian countries, United States and Japan were analyzed in detail and great differences with respect to the concepts and the quality of the programs were found. ${ }^{[99]}$ Part 2 focused on the position of biotechnology as a key technology, an analysis of international scientific trends, forecasts of biotechnology developments for the early $21^{\text {st }}$ century, identification of knowledge gaps of strategic importance, and opportunities and biotechnological options for the future. ${ }^{[100]}$ Important innovation areas for biotechnology research were described and aspects of modern biotechnology were presented in the fields of method and process development, microbial and enzymatic chemistry, natural products, biomaterials, medical-pharmaceutical applications, Human Frontier Science Program, genome analysis, neurobiology, agriculture, environmental biotechnology, bioenergy, renewable raw materials and bioelectronics. ${ }^{[100]}$ The report includes aspects of biological safety and a survey on research gaps among European and Japanese researchers from different areas of biotechnology. ${ }^{[100]}$ At the end of the report it is mentioned that a committee of experts, mandated by BBW and under the lead of SKB, created a 'Swiss Priority Program Biotechnology' in which the proposed areas and goals of research are in agreement with the findings of this early insight study and that this proposal had been presented in mid 1990 via BBW to the appropriate authorities for handling and decision-making. ${ }^{[100]}$

The SKB coordination group for biotechnology education created, under the lead of Oreste Ghisalba and Bernhard Sonnleitner and together with a group of 35 distinguished experts from Swiss universities, research institutions and industry, a series of recommendations for concrete measures for biotechnology education in Switzerland. ${ }^{[101]}$ In the course of this work more than 20 years ago major problems and ambitious goals in biotechnology education and national coordination were identified and analyzed from a broader perspective and ten recom- mendations of actions to be taken were defined by this group. [101] As this also required a common and clear understanding of the discipline biotechnology and in order to prevent misunderstandings, four commonly accepted definitions of biotechnology in Europe (see Table 1) were recommended, namely the EFB definition from 1981, the definition of the OECD in 1982 and of the EFB from 1989 and the concretization of the EFB Section on Biochemical Engineering in 1996.[101] Among the actions to be taken, recommended by this $\mathrm{SKB}$ coordination group for biotechnology education, was the continued evaluation of the biotechnology needs for academic and professional education and the use of the European Congress on Biotechnology 2003 in Basel as an excellent opportunity for that. ${ }^{[101]}$ In addition, the outsourcing in large companies was viewed as an opportunity to intensify the support of technological capabilities. ${ }^{[101]}$ Other recommendations included the content to be proposed from actual needs, putting together examples and case stories, as innovation was described to always occur at interfaces between disciplines and the communication who offers what and why. The quality of the basic and continuing education in biotechnology was seen to be inseparably connected with research and development and their application. ${ }^{[101]}$

\subsection{Swiss-Japanese Meetings on Bioprocess Development and Biotechnology}

This great series of bilateral meetings of scientists from Japan and Switzerland (Table 2) aimed at exchanging and discussing research results on bioprocesses and biotechnology was initiated by Prof. Armin Fiechter from ETH Zurich, who organized the first meeting in Interlaken in $1988,{ }^{[102]}$ in the same place and same year in which EFB was founded, with Prof. Armin Fiechter being among its founders. The meeting with the lead topic 'New Frontiers of Bioprocess Development' was launched by SKB

Table 1. Biotechnology definitions recommended by the coordination group on biotechnology education in Switzerland ${ }^{[84]}$

\begin{tabular}{|c|c|c|}
\hline $\begin{array}{l}\text { Scientific } \\
\text { Organisation }\end{array}$ & Year & Definition \\
\hline EFB & 1981 & $\begin{array}{l}\text { Biotechnology is the integrated use } \\
\text { of biochemistry, microbiology and } \\
\text { engineering sciences in order to } \\
\text { achieve technological (industrial) } \\
\text { application of the capabilities of mi- } \\
\text { croorganisms, cultured tissue cells } \\
\text { and parts thereof. }\end{array}$ \\
\hline OECD & 1982 & $\begin{array}{l}\text { Biotechnology is the application of } \\
\text { scientific and engineering principles } \\
\text { to the processing of materials by } \\
\text { biological agents to provide goods } \\
\text { and services. }\end{array}$ \\
\hline EFB & 1989 & $\begin{array}{l}\text { Biotechnology is the integration of } \\
\text { natural sciences and engineering } \\
\text { sciences in order to achieve the ap- } \\
\text { plication of organisms, cells, parts } \\
\text { thereof and molecular analogues for } \\
\text { products and services. }\end{array}$ \\
\hline SBES & 1996 & $\begin{array}{l}\text { Biochemical Engineering Science } \\
\text { represents the fundamental research } \\
\text { into all aspects of the interactions } \\
\text { between engineering and other } \\
\text { disciplines necessary to underpin } \\
\text { the development of industrial scale } \\
\text { biologically-based processes. }\end{array}$ \\
\hline
\end{tabular}


under the auspices of the 'Schweizerischer Schulrat'. ${ }^{[102]}$ Prof. Hideaki Yamada from Kyoto University acted as chairman of the conference and Prof. emeritus Saburo Fukui as honorary chairman. ${ }^{[102]}$ What made this first meeting to an important event according to the report were the conclusions drawn on the last day of the first Swiss-Japanese Meeting and the banquet speech of Prof. Heinrich Ursprung, president of the Schweizerischer Schulrat, who promised participation of the ETH in the future efforts for cooperation. ${ }^{[102]}$ It was described that Prof. Armin Fiechter proposed in a paper based on the results and conclusions of this first joint meeting that the Swiss government should support the development of biotechnology with public resources. ${ }^{[102,103]}$ The second Japanese-Swiss Meeting on Bioprocess Development in 1990 was hosted by the pioneer of numerous success stories of biotransformations developed into bioprocesses at industrial largescale, Prof. Hideaki Yamada from Kyoto University. In 1992, the third Swiss-Japanese Meeting, again organized by Prof. Armin Fiechter and his team, was held in Montreux under the auspices of SKB, ${ }^{[103]}$ while in 1994 a Japanese Committee chaired by Prof. Hideaki Yamada and honorary chairman Prof. Saburo Fukui organized the fourth edition of this impressive high-quality meeting in Kyoto. ${ }^{[104]}$ Prof. Oreste Ghisalba had a long-time interest in the experiences and success stories of modern biotechnology in Japan and what could be learned for the improvement of biotechnology in Europe. ${ }^{[105]}$ From his thorough analysis ten measures were derived which could improve the chances of success for biotechnology in Europe, among which the following three measures shall be pointed out: a) improvement of the dialogue between all involved stakeholders, b) improvement of the cooperation between universities, national research institutions and industries, and c) courage for long-term research programs essential for the sus- tainable development of industry and society. ${ }^{[105]}$ With his broad interests, network and understanding of the people, science, art and culture of Japan, the Ciba-Geigy laboratory in Takarazuka and his many visits to the country, he continued the tradition of these bilateral meetings and was very active from the Swiss side in the organization and realization of great and inspiring meetings over the next two decades, both in Japan and Switzerland, from the fifth Swiss-Japanese Meeting 1996 in Zermatt, which was designed within the broader context of biotechnology, to the thirteenth edition 2012 in Walzenhausen. Fig. 7 shows a selection of impressions from these meetings.

A full list of the titles of the meetings with their dates and locations can be seen in Table 2. All these joint meetings were well organized by committees from Switzerland, including Prof. Armin Fiechter, Prof. Oreste Ghisalba, Prof. Urs von Stockar, Dr. HansGeorg Leuenberger, Dr. Beat Mollet and Dr. Beat Wirz, as well as by committees from Japan, including Prof. Hideaki Yamada, Prof Saburo Fukui, Prof. Sakayu Shimizu, Prof. Hidehiko Kumagai, Prof. Yasuhisa Asano and Prof. Jun Ogawa, in wonderful places in Japan and Switzerland, with prominent speakers from industries and universities as well as biotechnet Switzerland, an R\&D consortium supported by the Swiss Government, providing exciting lectures on the state of the art in their field and a friendly and inspiring atmosphere for high quality information exchange and inspiring discussions. The tradition of these bilateral meetings clearly underlines the interest of both Switzerland and Japan in long-lasting, mutually beneficial and strong collaborations as well as exploring together innovative new roads in an ever changing world. As there were two separate conference series of traditional bilateral meetings, namely the German-Japanese Meetings on Enzyme Technology and the Swiss-Japanese Meetings on Biotechnology

Table 2. Swiss-Japanese Joint Meetings on Biotechnology and Bioprocess Development

\section{Meeting}

$1^{\text {st }}$ Swiss-Japanese Joint Meeting on Bioprocess Development

$2^{\text {nd }}$ Japanese-Swiss Joint Meeting on Bioprocess Development

$3^{\text {rd }}$ Swiss-Japanese Joint Meeting on Bioprocess Development

$4^{\text {th }}$ Japanese-Swiss Joint Meeting on Bioprocess Development

$5^{\text {th }}$ Swiss-Japanese Meeting on Biotechnology

$6^{\text {th }}$ Japanese-Swiss Meeting on Biotechnology

$7^{\text {th }}$ Swiss-Japanese Meeting on Biotechnology

$8^{\text {th }}$ Japanese-Swiss Meeting on Biotechnology

$9^{\text {th }}$ Swiss-Japanese Meeting on Biotechnology and Bioprocess Development

$10^{\text {th }}$ Japanese-Swiss Meeting on Biotechnology and Bioprocess Development

$11^{\text {th }}$ Swiss-Japanese Meeting on Biotechnology and Bioprocess Development

$12^{\text {th }}$ Japanese-Swiss Meeting on Biotechnology and Bioprocess Development

$13^{\text {th }}$ Swiss-Japanese Meeting on Biotechnology and Bioprocess Engineering

\section{Date}

25-27 July 1988

1990

25-27 October 1992

28-29 November 1994

2-4 October 1996

29-30 October 1998

10-12 September 2000

11-13 November 2002

12-15 September 2004

25-27 September 2006

26-28 October 2008

11-12 October 2010

4-6 November 2012

\section{Location}

Interlaken, Switzerland

Kyoto, Japan

Montreux, Switzerland

Kyoto, Japan

Zermatt, Switzerland

Toyama, Japan

Brienz, Switzerland

Takayama, Japan

Mürren, Switzerland

Kanazawa, Japan

Minusio, Switzerland

Toyama, Japan

Walzenhausen, Switzerland

continued by merging bilateral German-Japanese and Swiss-Japanese Meetings to a trinational Meeting:

$1^{\text {st }}$ Japan-Germany-Switzerland Workshop

for Enzyme Technology and Bioprocess Development
10-12 September 2019

Toyama, Japan 


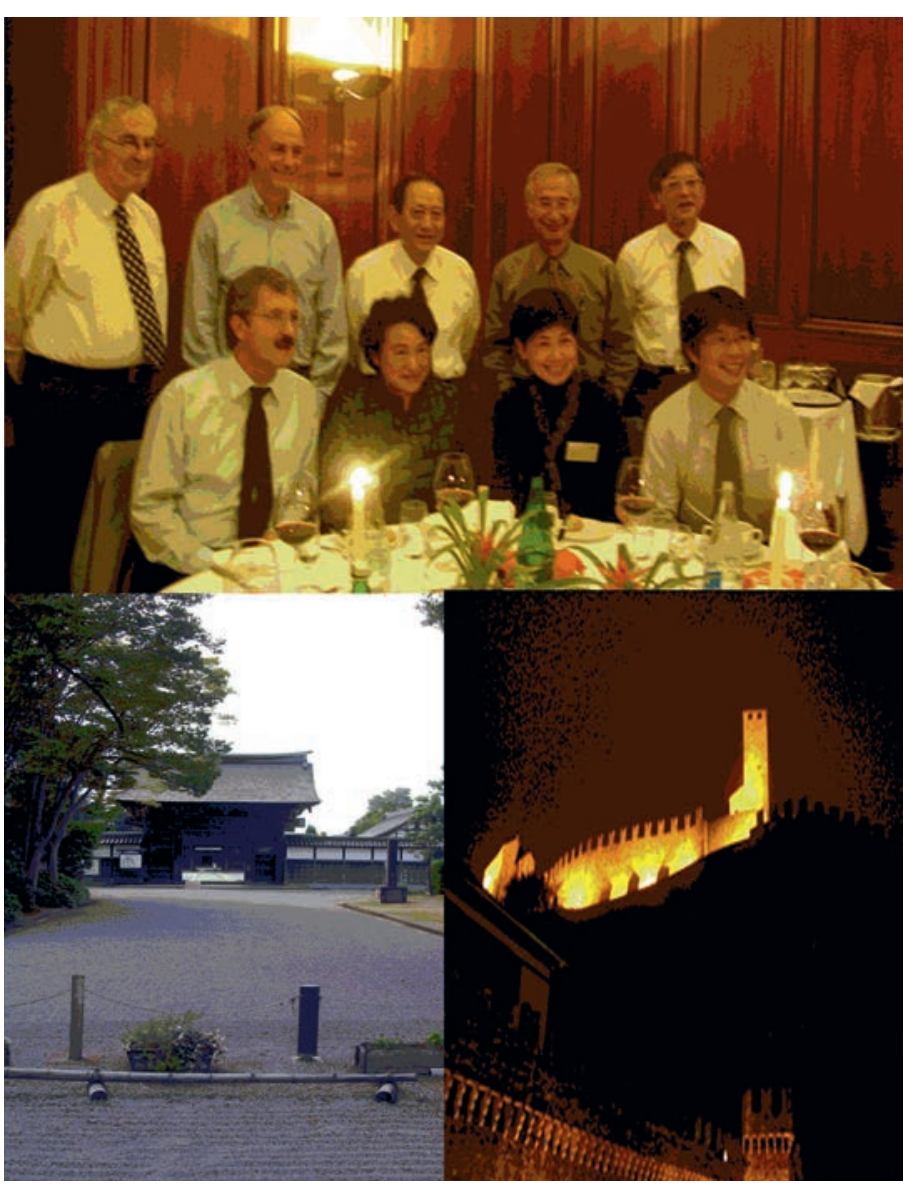

Fig. 7. Impressions from Swiss-Japanese Meetings on Biotechnology and Bioprocess Development.

and Bioprocess Development SKB, the corresponding meeting organizers from Germany, Switzerland and Japan decided to merge the two series of bilateral meetings into a new trinational meeting focused on Enzyme Technology and Bioprocess Development, also under the auspices of SKB. The first Japan-Germany-Switzerland Workshop on Enzyme Technology and Bioprocess Development was held from 10-12 September 2019 in Toyama, Japan, and its second edition will take place in Switzerland in 2021.

\section{Swiss Priority Program Biotechnology (SPP Biotech) and Action Plan Biotechnology in Switzerland}

The history of how this focused research program was created in Switzerland is very interesting and involved the formulation of a biotechnology project in 1989 under the lead of Prof. Ralph Hütter and the design of a concept of a research program with six modules under the lead of Prof. Jakob Nüesch in 1990,[106] in parallel with the early insight study mentioned in section 8.1. Although the research program of the Swiss Priority Program Biotechnology, in short SPP Biotech, was originally planned within a financial framework of 150 million $\mathrm{CHF}$, the budget was initially reduced to 83 million $\mathrm{CHF}$ after discussion in parliament, and due to the critical financial situation at that time in a second round of reduction to about 50 million CHF.[106] The Swiss National Science Foundation was given the responsibility for the realization of the SPP Biotech research program and the program direction was assigned to Prof. Oreste Ghisalba as the leader of the program and to Dr. Urs Christ from the Swiss National Science Foundation. ${ }^{[106]}$ The SPP Biotech program started with six specific modules focusing on the biotechnology topics of strategic interest to Switzerland and oriented to applications and problem solving, with module 1 dealing with processes for producing and purifying proteins for medical applications, module 2 on the bioengineering and material transformation areas of biotechnology, module 3 on neuro-informatics, module 4 on bioelectronics, module $5 \mathrm{~B}$ on biosafety research and biotechnology development and module 6 on the biotechnology of higher plants. ${ }^{[106]}$ In addition, SPP Biotech included a module on biotechnology education, but two of the submodules which were originally planned were transferred to the SPP Environment and two other submodules were postponed due to the reduced budget. ${ }^{[106]}$ During the implementation of SPP Biotech in the three phases of 1992-1996, 1996-1999 and 1999-2001, the modules 1,6 and the module education \& continuing education in biotechnology have been continued throughout the whole period, while module 2 was adapted to bioengineering and biocatalysis, food biotechnology was introduced as a new module and bioelectronics and neuroinformatics were united in one single module. The successful progress and realization of SPP Biotech has benefitted from being accompanied and evaluated by a committee of well-known national and international experts with its president Prof. Max M. Burger and installed by the Swiss National Science Foundation. ${ }^{[106]}$

The success of SPP Biotech as a first greater national initiative for developing biotechnology in Switzerland, [107,108] from 1992 until 2001, has been demonstrated by 868 supported scientists (without project leaders), about 70 patents/licenses, 100 processes and products, 1500 publications, 18 spin-off-companies, such as Cytos, Prionics, Glycart, ExcellGene, including about 400 newly created jobs and more than 100 companies, mainly SMEs, involved in SPP Biotech as transfer partners, about 100 million CHF from federal funds, about 56 million $\mathrm{CHF}$ contributed from third parties and more than 100 million CHF mobilized venture capital up to 2004. ${ }^{[109]}$ In addition to the great scientific and technological impact of the program, three new agencies on information/ communication, biosafety/technology assessment and technology transfer have been created to support Swiss Biotechnology. ${ }^{[110]}$

\section{Conferences}

From the many conferences in which Prof. Oreste Ghisalba was involved, the 11th European Congress on Biotechnology (ECB11) is highlighted here, as 2003 marked the 25th anniversary of both the first European Congress on Biotechnology which was held 1978 in Interlaken as well as the foundation of EFB during that event. ECB11 was organized by SKB in collaboration with the local Convention Center in Basel and on behalf of the Swiss societies that were members of EFB. Prof. Urs von Stockar was chair of the organizing committee, while Prof. Oreste Ghisalba and Prof. Peter Philippsen co-chaired the Scientific Committee.[111] President and Federal Chancellor Pascal Couchepin opened the congress, which attracted more than 1100 scientists from 57 countries and among them 250 Swiss attendees, with a speech getting broad response in the Swiss media. The scientific program included 6 excellent plenary lectures, 166 lectures in 31 symposia and 15 workshops and 618 poster contributions. Special attention beside the accompanying exhibition was given to the outreach of the congress to the public in Basel and Switzerland, to reach out to the young generation and to a public debate on biotechnology and food involving Simonetta Sommaruga and other prominent persons from politics, science and industry. This ECB11 Congress in Basel, ideal due to the presence of many chemical, pharmaceutical and biotechnological large companies and specialized SMEs demonstrated the achievements, importance and great future potential of Swiss biotechnology within and for Switzerland, for Europe and for the world as a whole. Last but not least, the congress inspired attendees and scientists to many new ideas and cooperations, such as the start of discussion among scientists performing work in biocatalysis within different Swiss industries on how to stimulate research and innovation on problems of common interest but larger than one company could stem and on how to find a balance between competition and cooperation, which ultimately led to the creation of the Swiss Industrial Biocatalysis Consortium (SIBC). 


\section{Legacy and Outlook}

Bridges of high quality, which were built by bringing together great ideas with thorough design and planning, the required knowledge and expertise as well as careful attention to details and implementation of plans while at the same time keeping in mind the big picture, represent great achievements creating new values but also connecting people and carrying them safely from one side to the other over long time periods. The many ongoing activities in many areas of science, industry and society described in this article as well as his life-long friendships are a lasting memorial to Oreste Ghisalba and his great number of high quality bridges, based on his broad experience, wide-ranging interests, generosity and extraordinary personality. As mentioned in a number of sections of this article, Prof. Oreste Ghisalba kept a fine balance between a bottom-up view of the deep details of the scientific and technological work and the top-down view of desired future developments in science, industry and society and what would be needed to make it possible. He pioneered the discovery of novel enzymes for applications of industrial interest and their applications from small to large scale and advocated the increased use of biotechnological processes, either as enzymatic or microbial whole-cell processes, in chemical production processes. As uncharted territories within the universe of enzymes in our biosphere or artificially designed and engineered enzymes have great future potential for fundamental breakthrough discoveries as well as for problem-solving and applications, global cooperation and initiatives are needed for the exploration of enzyme functions and for a continuum of innovation from fundamental research to the solutions of problems and practical applications. While certainly a multitude of gaps, problems and bottlenecks will have to be overcome, it will also, as in the past, be important today to build networks of motivated stakeholders willing to take up the global challenges which we are all faced with. The pioneering activities and programs of Prof. Oreste Ghisalba, from antibiotics, metabolites of pharmaceuticals, biodegradation, microbial enzymes and biotechnological processes to industrial biotransformations, were key factors for success in all these areas, in which current challenges require continued joint efforts. Numerous interfaces between biotechnology and chemistry offer many opportunities for building new bridges and for joint approaches. Building bridges between chemistry and biotechnology, integrating disciplines which were not connected traditionally and the courage to long-term research programs essential for a sustainable development of society and economy, give also clear direction signs for finding solutions to the challenges, for creating inspiring research environments towards exciting discoveries and for building new value creation chains towards a sustainable future not only for Switzerland, but globally.

Received: March 10, 2020

[1] P. Sensi, Rev. Infect. Dis. 1983, 5, S402.

[2] V. Prelog, Pure Appl. Chem. 1963, 7, 551.

[3] W. Wehrli, M. Staehelin, Bact. Rev. 1971, 35, 290.

[4] D. M. Rothstein, Cold Spr. Harb. Persp. Med. 2016, 6, a027011.

[5] O. Ghisalba, PhD Thesis, 'Untersuchungen über den Zusammenhang der Rifamycin-Chromophor-Biosynthese mit der Aromaten-Biosynthese über den Shikimisäure-Weg', University of Basel, Switzerland, 1978.

[6] H. G. Floss, T.-W. Yu, Chem. Rev. 2005, 105, 621

[7] O. Ghisalba, J. Nüesch, Experientia 1977, 33, 1688.

[8] O. Ghisalba, J. Nüesch, J. Antibiot. 1978, 31, 202

[9] O. Ghisalba, J. Nüesch, J. Antibiot. 1978, 31, 215.

[10] O. Ghisalba, P. Traxler, J. Nüesch, J. Antibiot. 1978, 31, 1124.

[11] O. Ghisalba, P. Traxler, H. Fuhrer, W. J. Richter, J. Antibiot. 1979, 32, 1267.

[12] O. Ghisalba, P. Traxler, H. Fuhrer, W. J. Richter, J. Antibiot. 1980, 33, 847.

[13] O. Ghisalba, H. Fuhrer, W. J. Richter, S. Moss, J. Antibiot. 1981, 34, 58.

[14] O. Ghisalba, J. Nüesch, J. Antibiot. 1981, 34, 64.
[15] J. J. Kibby, J. A. McDonald, R. W. Rickards, J. Chem. Soc., Chem. Commun. 1980, 16, 768 .

[16] O. Ghisalba, R. Roos, T. Schupp, J. Nüesch, J. Antibiot. 1982, 35, 74.

[17] P. Traxler, O. Ghisalba, J. Antibiot. 1982, 35, 1361.

[18] D. Gygax, O. Ghisalba, H. Treichler, J. Nüesch, J. Antibiot. 1990, 43, 324.

[19] O. Ghisalba, J. A. L.Auden, R. Schupp, J. Nüesch, 'The rifamycins: properties, biosynthesis, and fermentation' in 'Biotechnology of Industrial Antibiotics', Ed. E. J. Vandamme, Marcel Dekker, New York, 1984.

[20] O. Ghisalba, Chimia 1985, 39, 79.

[21] D. Gygax, M. Christ, O. Ghisalba, J. Nüesch, FEMS Microbiol. Lett. 1982, $15,169$.

[22] P. Hoehn, O. Ghisalba, T. Moerker, H. H. Peter, J. Antibiot. 1995, 48, 300.

[23] K. Goeke, P. Hoehn, O. Ghisalba, J. Antibiot. 1995, 48, 428.

[24] R. Wohlegemuth, Biotechnol. J. 2009, 4, 1253.

[25] M. Kittelmann, R. Lattmann, O. Ghisalba, Biosci. Biotech. Biochem. 1993, $57,1589$.

[26] G. Ramos, O. Ghisalba, H. P. Schär, B. Frei, P. Maienfisch, A. C. O'Sullivan, U.S. Patent No. 5,183,749. Washington, DC: U.S. Patent and Trademark Office, 1993.

[27] S. Weidner, K. Goeke, U. Trinks, P. Traxler, K. Ucci-Stoll, O. Ghisalba, Biosci. Biotech. Biochem. 1999, 63, 1497.

[28] M. Kittelmann, L. Oberer, W. Blum, O. Ghisalba, Chimia 1999, 53, 594.

[29] O. Ghisalba, M. Kittelmann, 'Preparation of drug metabolites using fungal and bacterial Strains' in 'Modern Biooxidation - Enzymes, Reactions and Applications', Ed. R. D. Schmid, V. B. Urlacher, Wiley-VCH, Weinheim, 2007.

[30] S. P. Hanlon, T. Friedberg, C. R. Wolf, O. Ghisalba, M. Kittelmann, 'Recombinant yeast and bacteria that express human P450s: bioreactors for drug discovery, -development and -biotechnology' in 'Modern Biooxidation - Enzymes, Reactions and Applications', Ed. R. D. Schmid, V. B. Urlacher, Wiley-VCH, Weinheim, 2007.

[31] M. Kittelmann, M. Serrano Correia, A. Kuhn, S. Parel, J. Kuhnol, R. Aichholz, M. Ponelle, O. Ghisalba, 'Biocatalytic Synthesis of 6-Hydroxy Fluvastatin using Mortierella rammaniana DSM 62752 in Shake Flask Culture and on Multi-gram Scale using a Wave Bioreactor' in 'Practical Methods for Biocatalysis and Biotransformations', Ed. J. Whitall, P. W. Sutton, John Wiley \& Sons, Chichester, 2009.

[32] M. Kittelmann, A. Kuhn, A. Riepp, J. Kühnöl, A. Fredenhagen, L. Oberer, O. Ghisalba, S. Luetz, 'Recombinant Human Cytochrome P450 Enzymes Expressed in Escherichia coli as Whole Cell Biocatalysts: Preparative Synthesis of Oxidized Metabolites of an mGlu5 Receptor Antagonist' in 'Practical methods for biocatalysis and biotransformations 2', Ed. J. Whitall, P. W. Sutton, John Wiley \& Sons, Chichester, 2012.

[33] O. Ghisalba, F. Heinzer, 'Methanol from methane - a hypothetical microbial conversion compared with the chemical process' in 'New Trends in Research and Utilization of Solar Energy through Biological Systems', Ed. H. Mislin, R. Bachofen, EXS 43: Experientia Supplementum, vol 43, Birkhäuser, Basel, 1982.

[34] O. Ghisalba, Chimica oggi-Chemistry today 1999, 17, 46.

[35] O. Ghisalba, Experientia 1983, 39, 1247.

[36] O. Ghisalba, M. Küenzi, Experientia 1983, 39, 1257.

[37] O. Ghisalba, M. Küenzi, Experientia 1983, 39, 1264.

[38] O. Ghisalba, P. Cevey, M. Küenzi, H. P. Schär, Conservation \& Recycling 1985, 8,47 .

[39] O. Ghisalba, F. Heinzer, M. Küenzi, 'Microorganisms of the Genus Pseudomonas and Process for degrading Compounds which contain Methyl Groups in Aqueous Solutions', U.S. Patent No. 4,490,471. Washington, DC: U.S. Patent and Trademark Office, 1984.

[40] O. Ghisalba, F. Heinzer, M. Küenzi, 'Microorganisms of the Genus Hyphomicrobium and Process for degrading Compounds which contain Methyl Groups in Aqueous Solutions', U.S. Patent No. 4,492,756. Washington, DC: U.S. Patent and Trademark Office, 1985.

[41] O. Ghisalba, 'Biocatalyzed Reactions', in 'New Trends in Synthetic Medicinal Chemistry', Ed. F. Gualtieri, Wiley-VCH, Weinheim, 2000.

[42] O. Ghisalba, M. Küienzi, H. P. Schär, Experientia 1986, 42, 108.

[43] O. Ghisalba, H. P. Schär, G. M. Ramos Tombo, 'Applications of Microbes and Microbial Enzymes in Environmental Control and Organic Synthesis' in 'Enzymes as catalysts in organic synthesis', Ed. M. P. Schneider, D. Reidel Publishing Company, Dordrecht, 1986.

[44] H. P. Schär, O. Ghisalba, Biotechnol. Bioeng. 1985, 27, 897.

[45] H. Lüdi, M. Garn, O. Ghisalba, H. P. Schär, Int. J. Environ. Anal. Chem. 1988, 33, 131.

[46] O. Ghisalba, M. Küenzi, G. M. Ramos Tombo, H. P. Schär, Chimia 1987, 41, 206.

[47] H. P. Schär, W. Holzmann, G. M. Ramos Tombo, O. Ghisalba, Eur. J. Biochem. 1986, 158, 469.

[48] H. P. Schär, P. Chemla, O. Ghisalba, FEMS Microbiol. Lett. 1985, 26, 117.

[49] H. P. Schär, D. Gygax, G. M. R. Tombo, O. Ghisalba, Appl. Microbiol. Biotechnol. 1988, 27, 451.

[50] R. Lattmann, O. Ghisalba, D. Gygax, H. P. Schär, E. Schmidt, Biocatalysis 1990, 3, 137. 
[51] M. Graf, A. Brunella, M. Kittelmann, K. Laumen, O. Ghisalba, Appl. Microbiol. Biotechnol. 1997, 47, 650.

[52] O. Ghisalba, M. Kittelmann, K. Laumen, P. Walser-Volken, U.S. Patent No. 6,235,516. Washington, DC: U.S. Patent and Trademark Office, 2001

[53] C. Dereppe, G. Bold, O. Ghisalba, E. Ebert, H. P. Schär, Plant Physiol. 1992, $98,813$.

[54] S. Weidner, M. Kittelmann, K. Goeke, O. Ghisalba, H. Zähner, J. Antibiot. 1998, $51,679$.

[55] O. Ghisalba, G. J. C. Marais, P. Martin, 'Method for treating cyclic phosphate compound', U.S. Patent No. 6,147,211, Washington, DC: U.S. Patent and Trademark Office, 2000.

[56] O. Ghisalba, G. J. C. Marais, P. Martin, 'Phosphorus containing cyclic nucleotides', U.S. Patent No. 6,340,754 B1, Washington, DC: U.S. Patent and Trademark Office, 2002.

[57] G. Marais, O. Ghisalba, Appl. Microbiol. Biotechnol. 2005, 66, 512.

[58] Y. Wasaki, T. Kawahara, H. Shimoi, K. Suzuki, O. Ghisalba, K. Kangawa, H. Matsuo, Y. Nishikawa, Eur. J. Biochem. 1991, 201, 551.

[59] O. Ghisalba, H. P. Schär, G. M. Ramos Tombo, Nachr. Chem. Tech. Lab. 1986, 34, 973 .

[60] G. M. Ramos Tombo, H. P. Schär, W. Zimmermann, O. Ghisalba, Chimia $\mathbf{1 9 8 5}, 39,313$.

[61] G. M. Ramos Tombo, H. P. Schär, O. Ghisalba, Agricult. Biol. Chem. 1987, $51,1833$.

[62] G.R. Tombo, H.P. Schär, X.F. Busquets, O. Ghisalba, Tetrahedron Lett. 1986, 27, 5707 .

[63] G. M. Ramos Tombo, H. P. Schär, I. Fernandez, X. Busquets, O. Ghisalba, 'Enantioselective reactions in aqueous and in organic media using carboxyl esterase fractions obtained from crude porcine pancreas lipase preparations', in 'Biocatalysis in Organic Media', Elsevier, Amsterdam, 1987.

[64] O. Ghisalba, R. Lattmann, D. Gygax, Rec. Trav. Chim. Pays-Bas 1991, 110, 263.

[65] K. Laumen, M. Kittelmann, O. Ghisalba, J. Mol. Cat. B: Enzymatic 2002, $19,55$.

[66] K. Laumen, O. Ghisalba, K. Auer, Biosci. Biotechnol. Biochem. 2001, 65 , 1977

[67] K. Laumen, O. Ghisalba, Eng. Life Sci. 2006, 6, 193.

[68] A. Brunella, M. Graf, M. Kittelmann, K. Laumen, O. Ghisalba, Appl. Microbiol. Biotechnol. 1997, 47, 515.

[69] P. Wahl, P. Walser-Volken, K. Laumen, M. Kittelmann, O. Ghisalba, Appl. Microbiol. Biochem. 1999, 53, 12.

[70] K. Laumen, A. Brunella, M. Graf, M. Kittelmann, P. Walser, O. Ghisalba, 'Pharmacochemistry Library: Trends in Drug Research II', vol. 29, Elsevier, Amsterdam, 1998.

[71] K. Laumen, O. Ghisalba, Biosci. Biotechnol. Biochem. 1994, 58, 2046.

[72] K. Laumen, O. Ghisalba. Biosci. Biotechnol. Biochem. 1999, 63, 1374.

[73] A. Brunella, O. Ghisalba, J. Mol. Catal. B: Enzymatic 2000, 10, 215.

[74] A. Brunella, M. Abrantes, O. Ghisalba, Biosci. Biotechnol. Biochem. 2000, 64, 1836.

[75] D. Gygax, H. Nachtegaal, O. Ghisalba, R. Lattmann, H. P. Schär, C. Wandrey, M. B. Streiff, Appl. Microbiol. Biotechnol. 1990, 32, 621.

[76] U. Kragl, D. Gygax, O. Ghisalba, C. Wandrey, 'Large scale production of $\mathrm{N}$-acetylneuraminic acid-Continuous asymmetric CC bond formation in an enzyme-membrane reactor', in '5th European Congress on Biotechnology', Munksgaard International Publisher, Copenhagen, 1990.

[77] U. Kragl, D. Gygax, O. Ghisalba, C. Wandrey, Angew. Chem. Int. Ed. 1991, $30,827$.

[78] U. Kragl, C. Wandrey, O. Ghisalba, D. Gygax, U.S. Patent and Trademark Office, U.S. Patent No. 5,071,750, 1991.

[79] U. Kragl, D. Gygax, O. Ghisalba, C. Wandrey, 'Aldolases for use in carbohydrate synthesis: enzymatic reaction engineering as a tool for process optimisation' in 'Biochemical Engineering for 2001', Ed. S. Furusaki, I. Endo, R. Matsuno, Springer-Verlag, New York, 1992.

[80] U. Kragl, M. Kittelmann, O. Ghisalba, C. Wandrey, Ann. N. Y. Acad. Sci. 1995, 750, 300

[81] M. Kittelmann, T. Klein, U. Kragl, C. Wandrey, O. Ghisalba, Ann. N. Y. Acad. Sci. 1992, 672, 444 .

[82] M. Kittelmann, O. Ghisalba, T. Klein, U. Kragl, C. Wandrey, 'Process for the production of activated sialic acids', U.S. Patent No. 5,334,514. Washington, DC: U.S. Patent and Trademark Office, 1994.

[83] M. Kittelmann, T. Klein, U. Krag1, C. Wandrey, O. Ghisalba, Appl. Microbiol. Biotechnol. 1995, 44, 59.

[84] U. Kragl, T. Klein, D. Vasic-Racki, M. Kittelmann, O. Ghisalba, C. Wandrey, Ann. N. Y. Acad. Sci. 1996, 799, 577.

[85] O. Ghisalba, D. Gygax, R. Lattmann, H. P. Schär, E. Schmidt, G. Sedelmeier, 'Verfahren zur Herstellung von Hydroxysäuren', Eur. Pat. Appl. 0347341 A1, Munich, European Patent Office, 1989.

[86] O. Ghisalba, D. Gygax, R. Lattmann, H. P. Schär, E. Schmidt, G. Sedelmeier, 'Process for the preparation of hydroxy acids', U.S. Patent No. 5,098,841. Washington, DC: U.S. Patent and Trademark Office, 1992.
[87] E. Schmidt, O. Ghisalba, D. Gygax, G. Sedelmeier, J. Biotechnol. 1992, 24, 315.

[88] K. Laumen, A. Brunella, M. Graf, M. Kittelmann, P. Walser, O. Ghisalba, 'New Biocatalytic Approaches for the Synthesis of Chiral Drugs, Intermediates, and Substrates', in 'Pharmacochemistry Library', 1998, 29, 17.

[89] O. Ghisalba, H. P. Meyer, R. Wohlgemuth, 'Industrial biotransformation' in 'Encyclopedia of Industrial Biotechnology: Bioprocess, Bioseparation, and Cell Technology', Ed. Flickinger, Wiley, 2009.

[90] H. P. Meyer, O. Ghisalba, J. E. Leresche, 'Biotransformations and the Pharma Industry' in 'Handbook of Green Chemistry, Vol. 3: Biocatalysis', Ed. R. H. Crabtree, Wiley-VCH, Weinheim, 2009.

[91] T. H. Friedberg, S. Hanlon, M. Kittelmann, O. Ghisalba, C. R. Wolf, Drug Metab. Rev. 2008, 40, 75 .

[92] M. Winkler, M. Geier, S. P. Hanlon, B. Nidetzky, A. Glieder, Angew. Chem. Int. Ed. 2018, 57, 13406.

[93] U. Pfaar, D. Gygax, W. Gertsch, T. Winkler, O. Ghisalba, Chimia 1999, 53, 590.

[94] M. Kittelmann, U. Rheinegger, A. Espigat, L. Oberer, R. Aichholz, E. Francotte, O. Ghisalba, Adv. Synth. Catal. 2003, 345, 825.

[95] M. Kittelmann, L. Oberer, R. Aichholz, O. Ghisalba, 'Synthesis of the Acyl Glucuronide of Mycophenolic Acid', in 'Practical Methods for Biocatalysis and Biotransformations', Ed. J. Whitall, P.W. Sutton, John Wiley \& Sons, Chichester, 2009

[96] R. Schneider, M. Hammel, E.G. Berger, O. Ghisalba, J. Nüesch, D. Gygax, Glycoconjugate J. 1990, 7, 589 .

[97] H. P. Schär, W. Märki, O. Ghisalba, H. B. Jenny, H. Rink, Ann. N. Y. Acad. Sci. 1988, 542, 302.

[98] R. Renneberg, A. Demain, 'Biotechnology for Beginners', Springer Verlag Berlin Heidelberg, 2008.

[99] O. Ghisalba. H. Vogel, 'Früherkennungsstudie zur Biotechnologie Teil 1: Staatliche Förderung der Biotechnologie - Eine Analyse öffentlicher Forschungs- und Entwicklungsprogramme der wichtgsten Industrieländer', A/62, Schweizerischer Koordinationsausschuss für Biotechnologie (SKB) \& Schweizerischer Wissenschaftsrat (SWR), Bern, 1990

[100] O. Ghisalba. H. Vogel, 'Früherkennungsstudie zur Biotechnologie Teil 2: Die Biotechnologie als Schlüsseltechnologie (Perspektiven und Prognosen) - Die Rolle der Biomoleküle als Informationsträger', A/63, Schweizerischer Koordinations- ausschuss für Biotechnologie (SKB) \& Schweizerischer Wissenschaftsrat (SWR), Bern, 1990.

[101] O.Ghisalba,B.Sonnleitner, 'EmpfehlungenfürKonkretisierungsmassnahmen zuhanden der Hochschulplanungskommission - Nationale Koordination der Aus- und Weiterbildung in Biotechnologie', Bericht der SKB-Gruppe für nationale Koordination der Aus- und Weiterbildung in Biotechnologie, 2000. https://www.sk-biotechnologie.ch/downloads/HPKbericht Dez2000. $p d f$

[102] H. M. Widmer, Chimia 1988, 42, 306. [103] H. G. W. Leuenberger, H. M. Widmer, Chimia 1993, 47, 59.

[104] H. G. W. Leuenberger, B. Sonnleitner, H. M. Widmer, Chimia 1995, 49, 293.

[105] O. Ghisalba, Chimia 1994, 48, 98

[106] O. Ghisalba, Chimia 1994, 48, 93

[107] O. Ghisalba, Chemistry today 1999, 17, 46.

[108] O. Ghisalba, H. Reutimann, Chimia 2000, 54, 141

[109] G. Escher, O. Ghisalba, S. Tomisawa, D. Alexakis, L. Buehler, U. Gantner, H. Hosbach, F. Reigel, S. Roulin, F. Salamé, E. Kottelat, I. Beretta, R. Grange, G. Haefliger, R. Kiener, 'Biotechnologie in der Schweiz: Aktionsplan', ISSN 1424-3342, Staatssekretariat für Bildung und Forschung SBF, Bern, 2007.

[110] F. Bieri, O. Ghisalba, O. Käppeli, H. Reutimann, 'International Aspects: National Profiles, Switzerland', in 'Encyclopedia of Ethical, Legal and Policy Issues in Biotechnology', Wiley \& Sons, 2002.

[111] U. Von Stockar, SATW Bull. 2004, 1/04, 61. License and Terms

\section{License and Terms}

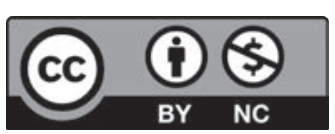

This is an Open Access article under the terms of the Creative Commons Attribution License CC BY_NC 4.0. The material may not be used for commercial purposes.

The license is subject to the CHIMIA terms and conditions: (http:// chimia.ch/component/sppagebuilder/?view=page \&id=12).

The definitive version of this article is the electronic one that can be found at doi:10.2533/chimia.2020.322 